\title{
Laminate Behavior for SiC Fiber-Reinforced Reaction-Bonded Silicon Nitride Matrix Composites
}

R.T. Bhatt

Propulsion Directorate

U.S. Army Aviation Research and Technology Activity-AVSCOM

Lewis Research Center

Cleveland, Ohio

and

R.E. Phillips

Sverdrup Technology, Inc.

NASA Lewis Research Group

Cleveland, Ohio

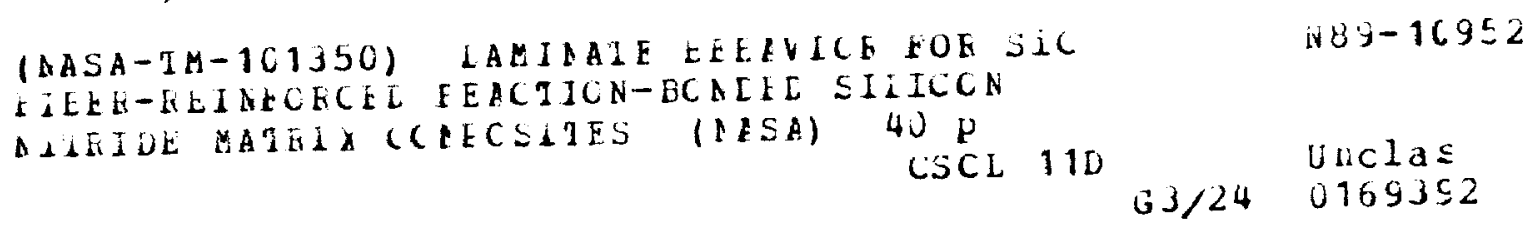

October 1988 


\section{$-$}




\title{
LAMINATE BEHAVIOR FOR SIC FIBER-REINFORCED REACTION-BONDED SILICON \\ NITRIDE MATRIX COMPOSITES
}

\author{
R. T. Bhatt \\ Propulsion Directorate \\ U.S. Army Research and Technology Activity - AVSCOM \\ Lewis Research Center \\ Cleveland, Ohio 44135 \\ and \\ R. E. Phillips \\ Sverdrup Technology, Inc. \\ NASA Lewis Research Center Group \\ Cleveland, Ohio 44135
}

\section{SUMMARY}

The room temperature mechanical properties of SiC fiber-reinforced reaction-bonded silicon nitride matrix composite laminates ( $S i C / R B S N$ ) have been measured. The laminates contained $\sim 30$ volume fraction of aligned $142-\mu \mathrm{m}$ diameter SiC fiber in a porous RBSN matrix. Three types of laminates studied were unidirectional laminates: (1) $[0]_{8},(2)[10]_{8}$, and (3) [45]8 and [90]8; cross plied laminates: $\left[\mathrm{O}_{2} / 90_{2}\right]_{s}$; and angle plied laminates: $\left[+45_{2} /-45_{2}\right]_{S}$. Each laminate contained eight fiber plies. Results for the unidirectionally reinforced composites tested at various angles to the reinforcement direction indicate large anisotropy in in-plane properties. In addition, strength properties of these composites along the fiber direction were independent of specimen gauge length and were unaffected by notches normal to the fiber direction. Splitting parallel to the fiber at the notch tip appears to be the dominant crack blunting mechanism responsible for notch insensitive behavior of these composites. In-plane properties of the composites can be improved by two-dimensional laminate construction. Mechanical property results for $\left[0_{2} / 90_{2}\right]_{S}$ and $\left[+45_{2} /-45_{2}\right]_{S}$ laminates showed that their matrix failure strains were similar to that for $[0]_{8}$ laminates, but their primary elastic moduli. 
matrix cracking strengths, and ultimate composite strengths were lower. The elastic properties of unidirectional, cross-ply, and angle-ply composites can be predicted from modified constitutive equations and laminate theory. Further improvements in laminate properties may be achieved by reducing the matrix porosity and by optimizing the bond strength between the SiC fiber and RBSN matrix.

\section{INTROOUCTION}

High performance silicon based ceramic materials have excellent high temperature strength, oxidation resistance, good thermal shock resistance, low density, and low coefficient of thermal expansion. These properties make them ideal candidates for high temperature applications. However, because of their brittle nature and nondeterministic strength properties, monolithic ceramics are not fully utilized in advanced aircraft engines. One method of improving their properties is by reinforcing them with continuous length ceramic fibers that do not degrade or form a chemical bond with the matrix during composite fabrication.

Recent studies (Refs. 1 and 2) have shown that the unidirectional reinforcement of a reaction-bonded silicon nitride matrix (RBSN) by high strength, high modulus, continuous length SiC fibers can yield a material which is much stronger and tougher than the unreinforced RBSN of comparable density. Because of its load carrying capability beyond the first matrix cracking stress and its low density and high temperature stability, SiC/RBSN composite material is a potential candidate for various aerospace structural and turbine applications. However, one major concern is that unidirectionally reinforced composites usually display large anisotropy in their in-plane properties. This severely restricts the use of the unidirectional composites in multi-axial loading applications. To overcome this anisotropy problem it may be necessary to fabricate two-dimensional laminates by stacking unidirectional lamina at 
different orientations relative to each other. The properties of these laminates are then governed not only by the properties of the unidirectional lamina but also by the lamination sequence.

The objectives of this study were several: (1) To determine effects of fiber orientation, specimen gauge length and machined notches on the mechanical properties of unidirectional SiC/RBSN composite laminates; (2) To study the deformation and fracture behavior of unidirectional, cross-ply, and angle-ply composite laminates; and (3) To determine the applicability of constitutive models and laminate theory for predicting elastic properties of composites.

\section{EXPERIMENTAL}

\section{COMPOSITE FABRICATION}

The SiC/RBSN composites were produced by conventional ceramic powder fabrication methods. The steps involved in the fabrication of the composites are shown in Fig. 1. The starting materials for the composites were SiC fiber mats and silicon powder cloth. The $142 \mu \mathrm{m}$ diameter SiC fiber used in this study was obtained from Textron Specialty Materials Division. This SiC fiber, designated as double coated SCS -6 by the manufacturer, contained a mixture of SiC/C on its outer surface. To prepare the fiber mats, the sic fibers were wound on a cylindrical drum and coated with a solution of a fugitive polymer binder in an organic solvent. After carefully drying, the fiber mat was cut to required dimensions.

For preparing the silicon powder cloths, high purity silicon powder obtained from Union Carbide was mixed with an additive (for enhancing nitridation), a fugitive polymer binder, and an organic solvent until a dough was formed. The dough was rolled to the desired thickness and cut to required dimensions.

For composite preform fabrication, alternate layers of SiC fiber mat and silicon cloth were stacked in a molybdenum die and hot pressed in vacuum or in 
a nitrogen environment at a suitable combination of temperature and pressure to produce a handleable preform. Using this fabrication method, composite preforms of $[0]_{8},[10]_{8},[45]_{8},[90]_{8},\left[0_{2} / 90_{2}\right]_{5}$, and $\left[+45_{2} /-45_{2}\right]_{5}$ were prepared. Each laminate contained eight fiber plies. The outermost layer of $\left[\mathrm{O}_{2} / \mathrm{SO}_{2}\right]_{S}$ laminate contained [0] fiber plies. Each preform contained 30 vol \% SiC fibers. For the $\left[\mathrm{O}_{2} / 90_{2}\right]_{S}$ and the $\left[+45_{2} /-45_{2}\right]_{S}$ ply constructions, the fiber ply lay-up was balanced about the laminate midplane to avoid any additional coupling stresses that may arise in the panel during cool down from the fabrication temperature or during later testing of composite specimens.

The composite preforms were then transferred to a horizontal nitridation furnace consisting of a recrystallized $\mathrm{Al}_{2} \mathrm{O}_{3}$ reaction tube with stainless steel end caps. The high purity nitrogen gas was flowed through the furnace before, during, and after nitridation. Nitridation of the composite was performed between 1200 and $1400^{\circ} \mathrm{C}$. Details of composite fabrication and nitridation conditions were reported elsewhere (Ref. 3). The nitrided composite panel was ground on emery paper to remove any loose surface $\mathrm{Si}_{3} \mathrm{~N}_{4}$ particles. Typical dimensions of the nitrided panels were 125 by 50 by $2.2 \mathrm{~mm}$.

\section{SPECIMEN PREPARATION}

Specimens for mechanical property measurements were prepared from composite panels by cutting and grinding them with a diamond impregnated abrasive wheel. For tensile tests, specimens of dimensions 125 by 12.7 by $2.0 \mathrm{~mm}$ were prepared by adhesively bonding glass fiber reinforced epoxy tabs at the specimen ends leaving $25 \mathrm{~mm}$ as the test gauge length. For the gauge length-strength study however, specimen gauge length was varied from 12 to $50 \mathrm{~mm}$. The axial and transverse strains were monitored using a wire wound strain gauge adhesively bonded to the specimen gauge section. The tensile tests were performed in an Instron machine at a crosshead speed of $1.26 \mathrm{~mm} / \mathrm{min}$. At each test condition, the strengths of five specimens were measured. 
For notch strength measurements, artificial $1 \mathrm{~mm}$ notches were cut to a depth of $3.0 \mathrm{~mm}$ in the width direction of the tensile test specimens at the midsection of the specimen gauge section. Both single and double notched specimens were prepared. Glass fiber reinforced epoxy tabs were bonded to these notched specimens as described previously and tensile tested at room temperature.

To determine the interlaminar shear strength of unidirectional composites, double notched specimens were used. The specimen geometry and the notch locations are shown in Fig. 2. Two types of specimens were prepared. One set contained notches in the thickness direction and the other set contained notches along the width direction. In all cases the notches were machined normal to the fiber direction. The specimen was placed between the platens of an Instron machine and tested in compression until failure. The interlaminar shear strength was then calculated from the measurement of the maximum failure load and the shearing area.

\section{RESULTS}

\section{UNIDIRECTIONAL LAMINATES}

\section{Tensile Properties}

The room temperature tensile stress-strain behavior for the $[0]_{8},[10]_{8}$, $[45]_{8}$, and $[90]_{8}$ laminates and for the unreinforced RBSN matrix of density similar to composite matrix are shown in Fig. 3. The stress-strain behavior for the $\mathrm{CO}_{8}$ laminate showed three distinct regions. In the initial region, the stress varied linearly with the strain up to an average stress level of $\sim 230 \mathrm{MPa}$ where the matrix was first observed to crack. In the second region, the stress-strain curve became nonlinear and displayed serrations due to multiple matrix cracking. At each serration, the stress on the specimen momentarily dropped and then recovered. In the third region, the stress varied linearly with the strain until maximum tensile stress was reached. 
Beyond this point the specimen showed no load carrying capacity and fractured. In contrast, stress-strain behaviors for the $[10]_{8},[45]_{8}$, and $[90]_{8}$ laminates and for the unreinforced matrix exhibited entirely different behavior. These laminates showed essentially linear behavior until final fracture. At the ultimate stress level, the specimens failed catastrophically.

The variations of primary tensile modulus and the ultimate tensile strength for these laminates as a function of $\theta$, the angle between the direction of the applied load and the direction of reinforcement, are shown in Figs. 4 and 5. Both figures indicate that as $\theta$ is increased, the primary tensile modulus as well as the ultimate strength decreased initially and then leveled off. However, the effect of $\theta$ is greater on the ultimate strength properties than on the primary elastic modulus. Also shown in Fig. 5 is the first matrix cracking stress for $[0]_{8}$ laminate. As expected, the $[0]_{8}$ laminates by far yielded the best properties when compared to the off-axis laminates.

The elastic and fracture property data for $[0]_{8}$ and $[90]_{8}$ laminates, as well as $\left[\mathrm{O}_{2} / 90_{2}\right] \mathrm{S}$ and $\left[+45_{2} /-45_{2}\right] \mathrm{S}$ laminates, and unreinforced RBSN obtained from their respective stress-strain curves are shown in Table I. The symbols $E_{x x}, E_{s s}, G_{x y}$, and $\tau_{x y}$ in Table I refer to primary and secondary elastic moduli along the loading direction, shear modulus, and Poisson's ratio respectively in laminate coordinates. Each data point in Table I represents an average of five tests. The scatter in the data represents one standard deviation.

Optical observation of $[0]_{8}$ specimens unloaded from different stress levels to the ultimate composite fracture stress showed the phenomena associated with successive stages of failure in the stress-strain behavior. At the stress level corresponding to the deviation from linearity, the specimen showed matrix cracking normal to the applied load. Unless the specimen was 
observed immediately after unloading, the matrix crack had a tendency to close completely. With continued stressing, the matrix blocks on either side of the crack loaded up until they cracked. This process continued until matrix blocks ceased to crack. This point corresponded to the end of the serrated stressstrain range shown in Fig. 3. In addition, at this point regularly spaced matrix cracks were clearly visible within the gauge section as illustrated in Fig. 6. The average matrix block size or crack spacing was $0.8 \pm 0.2 \mathrm{~mm}$. Specimens stressed between the stress corresponding to the end of the serrated range and the ultimate fracture stress showed no additional microstructural features. At ultimate stress, the specimen failed catastrophically and showed brushy and broomy fracture with little matrix around the fibers. Detailed examination of the fractured specimen indicated that SiC fiber fracture occurred within a damage zone of $\sim 3 \mathrm{~mm}$.

In contrast, examination of off-axis laminates stressed up to ultimate stress showed no evidence of damage until the ultimate stress where they failed catastrophically. Figure 7 shows typical tensile fractured specimens of $[10]_{8},[45]_{8}$, and $[90]_{8}$ laminates. Included in the figure for comparison purposes is the fractured specimen of a $\mathrm{CO}_{8} 8$ laminate. Comparison of fractured specimens indicates that only the $[0]_{8}$ laminate displayed fracture characteristics typical of a tough composite, that is, fiber pull out and graceful failure. On the other hand, all off-axis laminates typically fractured in a brittle manner and the fracture occurred invariably by fiber/matrix interface splitting as shown in Fig. 7.

Effect of Gage Length on Strength

The influence of gauge length on the room temperature tensile properties of $[0]_{8}$ laminates was determined. For this study the specimen gauge length was varied from 12 to $50 \mathrm{~mm}$. The properties measured were the matrix fracture 
strength and the ultimate composite strength. The results reported in Table II indicate no influence of specimen gauge length on axial properties.

Effect of Notches on Strength

The effect of notches on the room temperature strength properties of unidirectional laminates were determined. The results are presented in Table III together with the strength data for unnotched specimens. The matrix fracture strength and the ultimate composite strength for the notched laminates were measured based on net cross sectional area. Results presented in Table III show no significant effect of notches on tensile properties of $\mathrm{CO}_{8}$ laminates. This behavior is significantly different from that of monolithic ceramics where surface cracks and notches are known to cause premature failure and lower strength (Ref. 4).

To determine the mechanism of notch insensitivity in SiC/RBSN composites, a notched specimen was observed during tensile testing. Initially up to an average stress level of $\sim 65 \mathrm{MPa}$, the specimen showed no indication of damage. As the specimen was stressed beyond this stress level, cracks were formed at the notch tip along the fiber/matrix interface which eventually resulted in vertical cracking, as shown in Fig. 9. With continued stressing, the notched specimen behaved similarly to the unnotched specimen and falled upon reaching its ultimate stress. From these observations, it can be concluded that vertical splitting is probably the major stress relieving mechanism responsible for crack tip blunting and hence for the notch insensitivity in these composites.

\section{Shear Properties}

Interlaminar shear strength. - For interlaminar shear strength measurements, short beam and double notched shear tests have been suggested (Ref. 5). Both of these tests are without ASTM standards. In this study, the double notch method was employed. To determine the influence of fiber 
distribution on interlaminar shear strength, two sets of specimens were used. One set contained notches along the thickness direction (along the hot pressing direction) and the other set along the width direction (along a direction normal to hot pressing direction) (Fig. 2). Test results indicate that the former set showed the interlaminar shear strength value of $40 \mathrm{MPa}$ and the latter set a value of $100 \mathrm{MPa}$. This difference in the strength can be traced to the arrangement of fiber plies relative to notch location. For specimens containing notches cut along the thickness direction, the two opposing notches end on the same fiber ply. These specimens on testing failed in shear. For specimens having notches along the width direction, the notches ended on different fiber row. On testing, these specimens failed by a combination of compression and shear. It can be concluded from these observations that the value of $40 \mathrm{MPa}$ reflects the true interlaminar shear strength of the laminates. In-plane shear properties. - Four methods have been suggested in the composite literature (Refs. 6 and 7) for measuring in-plane shear properties of composite laminates. These are the $\left[+45_{2} /-45_{2}\right] \mathrm{s}$ laminate test, the $10^{\circ}$ offaxis test, the rail shear test, and the torsion test. In this study, in-plane shear modulus was derived from the axial tensile stress-strain data for the $\left[+45_{2} /-45_{2}\right]$ s laminates. The details of the measurements will be discussed in the next section.

$\left[0_{2} / 90_{2}\right]_{S}$ Cross-ply and $\left[+45_{2} /-45_{2}\right]_{S}$ Angle-ply Laminates

Tensile properties. - Typical room temperature tensile stress-strain behaviors for the $\left[0_{2} / 90_{2}\right] S$ and $\left[+45_{2} /-45_{2}\right]_{S}$ SiC/RBSN composite laminates are shown in Fig. 10. For comparison purposes also shown in Fig. 10 are the stress-strain curves for the $\mathrm{CO}_{8}$ and $[90]_{8}$ laminates. In general, the stressstrain behavior for the $\left[0_{2} / 90_{2}\right] s$ laminates appeared similar to that for the $\mathrm{CO}_{8}$ laminates. Initially stress varied linearly with strain up to $\sim 130 \mathrm{MPa}$. Above this stress level, the stress-strain curve became nonlinear. Beyond 
$\sim 150 \mathrm{MPa}$, stress again varied linearly with strain until composite fracture. Upon reaching the ultimate stress, the specimen broke catastrophically with no further load bearing capacity.

On the other hand, the stress-strain behavior for the $\left[+45_{2} /-45_{2}\right]_{S}$ laminates displayed only two deformation regions. In the first region, the stress increased proportionately with strain up to $\sim 80 \mathrm{MPa}$. Beyond this stress level, the stress-strain behavior became nonlinear. This nonlinearity prevailed until an ultimate stress of $\sim 90 \mathrm{MPa}$. Even after ultimate stress, the specimen possessed substantial load carrying capability. This behavior is quite different from that observed for other laminates.

Comparison of the stress-strain curves for the laminates shown in Fig. 10 indicates that the primary modulus, the matrix cracking stress, and the ultimate composite strength for the $\left[0_{2} / 90_{2}\right]_{S}$ and $\left[+45_{2} /-45_{2}\right]_{S}$ laminates were significantly lower than those for the $[0]_{8}$ laminates. An interesting point to note here is that the strain level at which the deviation from the initial 1 inear region occurred was 0.1 percent strain for all laminates except for the $[90]_{8}$ laminate. For $[0]_{8}$ laminates, this strain value corresponds to the initial matrix cracking strain, but for $\left[0_{2} / 90_{2}\right]_{8}$ or $\left[+45_{2} /-45_{2}\right]_{S}$ laminates, it may correspond either to the first matrix cracking strain or to the fiber/ matrix debonding strain. The reasons for the deviation or the nonlinearity will be discussed in the next section. In comparison, the ultimate failure strain for the $[90]_{8}$ laminate is $\sim 0.03$ percent which is nearly a third that of the strain corresponding to the deviation from linearity for the $[0]_{8}$ and $\left[\mathrm{O}_{2} / 9 \mathrm{O}_{2}\right]_{S}$ laminates. The room temperature mechanical property data derived from the stress-strain curves for $\left[\mathrm{O}_{2} / 9 \mathrm{O}_{2}\right]_{S}$ and $\left[+45_{2} /-45_{2}\right]_{S}$ laminates are tabulated in Table I.

To identify the sequence of events that led to their final failure, the $\left[\mathrm{O}_{2} / 90_{2}\right]_{S}$ cross-ply laminate specimens were loaded to predetermined stress 
levels, unloaded, and then observed under an optical microscope. A series of optical photographs of a specimen taken after stressing to different stress levels is shown in Fig. 11 to illustrate the damage features. Up to a stress level of $150 \mathrm{MPa}$, specimens showed no damage. Above this stress level, a single matrix crack was first seen. With continued loading, regularly spaced matrix cracks were seen normal to the loading direction throughout the gauge length. These cracks propagated through the thickness of the specimen. The average matrix crack spacing was $0.8 \mathrm{~mm}$. This crack spacing was similar to that measured for $[0]_{8}$ laminates. With continued stressing, longitudinal cracks were formed mostly along the [0] plies. In some specimens longitudinal cracks parallel to and in the [90] plies were also seen. At ultimate stress, the specimen fractured catastrophically and the fracture surface showed extensive fiber pullout.

Examination of $\left[+45_{2} /-45_{2}\right]$ s laminate specimens that were unloaded from different stress levels indicated slightly different deformation features from that of $\left[\mathrm{O}_{2} / \mathrm{gO}_{2}\right]_{\mathrm{S}}$ laminates. Up to a stress level of $80 \mathrm{MPa}$, specimens showed no evidence of damage. Above this stress level, however, matrix cracks were seen nearly normal to the loading direction as indicated in Fig. 12, but damage occurred in a small region. This behavior is significantly different from that observed for the $[0]_{8}$ and $\left[0_{2} / 90_{2}\right]_{S}$ laminates where damage occurred throughout the gauge section due to regular matrix cracks. At ultimate load, $\left[+45_{2} /-45_{2}\right] s$ laminates failed gracefully by a combination of tension and shear mode.

As discussed earlier, the in-plane shear properties for the unidirectional composites can be inferred from the tensile stress-strain curve for the $\left[+45_{2} /-45_{2}\right]$ s laminates. The theoretical basis for this relationship has been discussed in detail in Ref. 6. From measurements of transverse and axial strains at any applied stress level in the initial linear region of the 
stress-strain curve for the $\left[+45_{2} /-45_{2}\right]_{S}$, the shear modulus, $G_{12}$, can be calculated from the equation (Ref. 6),

$$
G_{12}=\sigma_{x} / 2\left(\varepsilon_{x}-\varepsilon_{y}\right)=E_{x x} / 2\left(1+\nu_{x y}\right)
$$

where $\sigma_{x}$ is the applied stress, $\varepsilon_{x}$ is the longitudinal strain, $\varepsilon_{y}$ is the transverse strain, $E_{x x}$ is the elastic modulus along the loading axis, and $v_{x y}$ is Poisson's ratio. The subscripts $x, y$ and 1,2 refer to laminate and material principle coordinate systems, respectively. This nomenclature is used henceforth. The specimen testing and data analysis were performed according to ASTM standard D 3518-76. Substituting the values of $E_{x x}=78 \mathrm{GPa}$ and $v_{x y}=$ 0.36 from Table I for $\left[+45_{2} /-45_{2}\right]_{S}$ laminates in Eq. (1), we obtained a value of $29 \mathrm{GPa}$ for $\mathrm{G}_{12}$.

If the $\left[+45_{2} /-45_{2}\right]$ s 1 aminate exhibits elastic behavior until fracture, then it is possible to estimate the in-plane shear strength of the unidirectional composites. Usually one half the ultimate tensile strength of $\left[+45_{2} /-45_{2}\right]_{S}$ laminates is considered as the in-plane shear strength. Since the stress-strain curve for the $\left[+45_{2} /-45_{2}\right]_{S}$ laminates displayed a well defined nonlinear region in its stress-strain behavior, no attempt was made to calculate its in-plane shear strength.

\section{DISCUSSION}

UNIDIRECTIONAL LAMINATES

\section{Elastic Properties}

The mechanical property results for unidirectionally reinforced SiC/RBSN composites tested at various angles to the reinforcing direction indicate anisotropy in in-plane properties. From constitutive models and laminate theory it is possible to predict the in-plane properties of a strongly bonded fiber reinforced metal or polymer matrix composites, but for a weakly bonded fiber reinforced ceramic matrix composites (CMC) such as SiC/RBSN, these constitutive models cannot be employed in the present form. However, by simple 
approximations, it can be shown that these models can be utilized to predict the elastic properties of weakly bonded CMC's. Based on the validity of this simple CMC theory, methods for improving mechanical properties of SiC/RBSN can then be suggested.

If we treat the unidirectional composite lamina as an orthrotropic material, then under a plane stress condition, its stress-strain relationship along any arbitrary angle, $\theta$ to the primary material directions can be predicted provided the elastic constants in those directions are known. Since elastic properties of a orthotropic solid can be uniquely described by knowing four independent elastic constants, it is possible to obtain relationships for the laminate elastic properties as a function of $\theta$ (Refs. 6, 8, and 9). These relationships are

$$
\begin{aligned}
& 1 / E_{x x}=\left(1 / E_{11}\right) \cos ^{4} \theta+\left(1 / G_{12}-2 v_{12} / E_{11}\right) \sin ^{2} \theta \cdot \cos ^{2} \theta+1 / E_{22} \sin ^{4} \theta \\
& 1 / E_{y y}=\left(1 / E_{11}\right) \sin ^{4} \theta+\left(1 / G_{12}-2 v_{12} / E_{11}\right) \sin ^{2} \theta \cdot \cos ^{2} \theta+1 / E_{22} \cos ^{4} \theta \\
& 1 / G_{x y}=2\left[\left(2 / E_{11}+2 / E_{22}+4 v_{12} / E_{11}-1 / G_{12}\right) \sin ^{2} \theta \cdot \cos ^{2} \theta\right. \\
& \left.+1 / G_{12}\left(\sin ^{4} \theta+\cos ^{4} \theta\right)\right] \\
& v_{x y}=E_{x x}\left[v_{12} / E_{11}\left(\sin ^{4} \theta+\cos ^{4} \theta\right)-\left(1 / E_{11}+1 / E_{22}-1 / G_{12}\right) \sin ^{2} \theta \cos ^{2} \theta\right.
\end{aligned}
$$

where $E_{x x}$ is the elastic modulus along the loading direction, $E_{y y}$ is the elastic modulus normal to loading direction, $G_{x y}$ is the in-plane shear modulus, and $v_{x y}$ is the Poisson's ratio in the laminate coordinate system. The symbols $E_{11}, E_{22}, G_{12}$, and $v_{12}$ are the respective elastic constants in the material coordinate system. In Eqs. (2) to (5) there are four independent elastic constants namely $E_{11}, E_{22}, v_{12}$, and $G_{12}$. Substituting these constants in Eqs. (2) to (5), one can calculate the variation of elastic properties with $\theta$.

These four independent elastic constants can either be calculated from the constituent properties or be measured from composite testing. Several closed form expressions exist in the literature for the calculation of these constants 
from constituent properties. The expressions used for calculating these four constants are given in Appendix A. In deriving these expressions it is assumed that strong bonding exists between the fiber and the matrix. The calculation shows that out of the four elastic constants calculated for SiC/RBSN, only two elastic constants, $E_{11}$ and $\tau_{12}$, which refer to on-axis elastic properties, agreed with the measured values. On the other hand, if we assume that the fiber contribution is zero in Eqs. (A-2) and (A-5), then the calculated values of the other two elastic constants, $E_{22}$ and $G_{12}$, which refer to off-axis elastic properties, were in reasonable agreement with the measured values. The implication of this finding is that fibers contribute to composite elastic properties along the reinforcement direction, but they do not contribute in off-axis directions. Therefore, it is reasonable to conclude that SiC/RBSN composites do not behave as a strongly bonded composite.

Further evidence for weak bonding comes from the fractographic results. As discussed previously, the composite specimens stressed along the reinforcement direction to stress levels above the matrix fracture stress developed the matrix macro-cracks normal to the fiber direction. These matrix macro-cracks were deflected at the fiber/matrix interface causing minimal damage to fibers. In fact, fibers kept the integrity of the composite specimen until its final fracture. This multiple matrix cracking behavior seems possible only when the bonding between the fiber and matrix is weak. Furthermore, examination of failed off-axis laminates have shown that laminate fracture originated from fiber/matrix interface splitting which is also an indication of a weak bond between fibers and matrix. On the other hand, if the fibers were bonded strongly to the matrix, the composite on stressing above the matrix cracking stress would have failed in a brittle manner (Ref. 3). Since these observations strongly suggest that the bonding between SIC fibers and RBSN matrix bonding is weak, the question arises as to why the 
calculated values for the elastic constants, $E_{11}$ and $v_{12}$, based on a strong bonding approximation, agree with the measured values for these constants for the weakly bonded SiC/RBSN composites. It can be argued that, for a weakly bonded CMC stressed along the reinforcement direction; adequate load transfer can occur between the fibers and the matrix, provided the fibers are in intimate contact with the matrix. The radial compressive stresses acting on the fibers from the Poisson's effect may also help in efficient load transfer. Thus, as long as adequate load transfer occurs at the interface, the fibers can contribute to elastic properties of a weakly bonded composite, and the elastic constants, $E_{11}$ and $v_{12}$, can be calculated based on the strong bond approximation. On the other hand, when a weakly bonded composite is stressed in any off-axis direction, the fibers tend to debond from the matrix because of a transverse tensile stress component acting on the interface. In other words, fibers do not contribute to off-axis elastic properties of the SiC/RBSN composites, and the values of elastic constants $E_{22}$ and $G_{12}$ calculated assuming zero fiber contribution in the strongly bonded approximation may then be expected to agree reasonably well with the measured values.

From the simple equations given in Appendix $A$, we have calculated two sets of four elastic constants; one set for strongly bonded composites and the other set for weakly bonded composites $\left(E_{f 22}=0\right)$. Both sets are calculated from constituent properties. Using these two sets of elastic constants and Eqs. (2) to (5), one can predict the variation of elastic constants with $\theta$. The results of these calculations for weakly bonded SiC/RBSN composites are plotted in Figs. 13 and 14. In Fig. 15, the primary elastic moduli predicted from laminate theory for strongly and weakly bonded composites are compared with the experimental data. The solid line in Fig. 15 represents the predicted variation of $E_{x x}$ with $\theta$ for the weakly bonded case: the dashed line represents the variation obtained for the strongly bonded case; and the filled 
points represent the measured elastic moduli for the on and off-axis laminates. Fig. 15 shows that the modulus variation calculated based on the weakly bonded composite model agrees well with the measured values of moduli for off-axis laminates.

\section{Strength Properties}

Axial strength. - In general, when a unidirectionalily reinforced composite laminate is stressed in a direction parallel to the reinforcement, the laminate extends elastically until one of the components fractures. Up to the point of fracture, the stress in the laminate varies linearly with the strain and at any strain level the stress in the composite, $\sigma_{C}$, is given by Hooke's law

$$
\sigma_{C}=E_{C} \varepsilon_{C}
$$

where $E_{C}$ is the composite modulus and $\varepsilon_{C}$ is the composite strain.

When the unidirectional SiC/RBSN laminate was stressed along the

reinforcement direction, the RBSN matrix fractured first, because it is a weaker phase than the SiC fiber. In addition, because of the weak frictional or mechanical bond formed between the SiC fiber and the RBSN matrix, the advancing matrix cracks deflected at the fiber/matrix interface causing minimal damage to the fiber surface. This allowed the SiC fibers to bear part of the load previously carried by the RBSN matrix. This will be discussed further in a later section. The strain level at which RBSN matrix fractured can be obtained from Eq. (5) assuming $\varepsilon_{f}=\varepsilon_{m}=\varepsilon_{c}$, that is

$$
\varepsilon_{m}=\sigma_{c} / E_{C} \text {. }
$$

In this equation, the primary composite modulus, $E_{c}$, can be obtained from the rule of mixtures, but the composite stress at which the matrix fractures is difficult to calculate entirely based on constituents properties because it is influenced by factors such as bridging of matrix flaws by fibers, residual stresses developed in the matrix during cool down from the fabrication temperature, interfacial shear strength between the fiber and the matrix, etc. 
For $[0]_{8}$ laminates, the strain for matrix fracture occurred at 0.1 percent which is similar to that measured for the unreinforced RBSN matrix. This suggests that reinforcement by large diameter SiC fibers in RBSN matrix had a marginal influence on its fracture strain. On the other hand, studies (Refs. 10 and 11 ) have shown significant improvement in matrix fracture strain for glass matrices reinforced by small diameter carbon or SiC fibers.

Although the micro-crack bridging mechanism is apparently not operative in the current SiC/RBSN composites, other methods may be used to increase the strain or stress to failure of the matrix such as increasing the volume fraction of the fibers, or improving the matrix density. Of course, use of smaller diameter fibers as reinforcement should enhance the micro-crack bridging mechanism. From a practical point of view, it is desirable to have as high a first matrix fracture stress as possible because this stress is probably the upper design stress of the composite. Use of the composite beyond this point depends on environmental stability of the fibers at the use temperature. Environmental gases can readily diffuse through the cracked matrix and react with fibers causing either loss of the fiber surface coating or a stronger bond between the fibers and matrix. Both of these reactions are known to decrease the strain capability of the composite beyond the first matrix cracking stress. On the other hand, if the fibers are environmentally stable and do not bond with the matrix under the operating conditions, the composite can be used at stress levels beyond the matrix cracking stress.

Above the first matrix cracking stress, the $[0]_{8}$ SiC/RBSN composite laminates showed additional matrix micro-cracks. This micro-cracking process was continued until the remaining matrix blocks could no longer be loaded above their fracture strains. From the Aveston, Cooper, and Kelly theory (Ref. 10), it is possible to determine the interfacial shear strength between the fiber and matrix from the measurement of limiting matrix crack spacing, the first 
matrix fracture stress and the elastic properties of the fiber and the matrix. The relationship between interfacial shear strength and matrix crack spacing is given in Appendix $B$. The calculated value of interfacial shear strength for SiC/RBSN based on the equation given in Appendix $B$ is $18 \mathrm{MPa}$. This value is higher than the value of 10 to $13 \mathrm{MPa}$ reported previously for the same composite (Ref. 3). The higher interfacial shear strength measured in this study probably reflects better bonding between the fibers and matrix.

Beyond the nonlinear region, the deformation of the composite is entirely controlled by the fibers since the fractured matrix bears hardly any load. Because the SiC fibers are essentially elastic up to fracture, a second linear region was observed in the stress-strain curve. The secondary modulus of the composite can be estimated from Eq. $(A-1)$ of Appendix A assuming the matrix contribution to composite modulus is zero, that is,

$$
E_{C}^{S}=E_{f} V_{f}
$$

Substituting $E_{f}=390 \mathrm{GPa}$ (Ref. 12) and $V_{f}=0.3$ in Eq. (13), we obtained $E_{C}^{5}=117 \mathrm{GPa}$. This estimated value is 14 percent higher than the average measured value of $103 \pm 12 \mathrm{GPa}$. In this calculation it is assumed that the $\mathrm{SiC}$ fibers remain intact until ultimate failure and the volume fraction of fibers at fracture is the same as the as-fabricated composite. However, the lower measured value of $E_{C}^{S}$ suggests that the volume fraction of fibers used for the calculation may be in error because of possible continuous fracture of SiC fibers in the second linear region. In other words the effective fiber fraction is lower than the fiber fraction used for the calculation.

As described previously, the ultimate strength of the composite is controlled by the fibers. Therefore, knowing the bundle strength of the fiber, the ultimate tensile strength of the composite, $\sigma_{C}$, can be estimated from the equation (Ref. 13),

$$
\sigma_{c}=\sigma_{f}^{B B V_{f}}
$$


where $\sigma_{f}^{B}$ is the fiber bundle strength and $V_{f}$ is the fiber volume fraction in composite. Fiber bundle strength can be estimated from the tensile testing of either composite specimens with the matrix removed from the gauge section or of individual fibers removed from the composite. If we assume the fibers in the bundle are parallel and not touching and behave completely independently of each other, then on stressing the fiber bundle, the individual fibers fail in sequence, beginning with the weakest. At each fiber break, load redistribution occurs and the remaining fibers bear the load previously carried by the broken fiber. Upon reaching the composite ultimate fracture strength, the remaining intact fibers are overloaded and break at once. The bundle strength of the fibers, $\sigma_{f}^{B}$, based on the original area of the fibers is represented by Eq. $(13)$

$$
\sigma_{f}^{B}=\sigma_{0}(L / d)^{-1 / m}(m e)^{-1 / m}
$$

where $\sigma_{0}$ is a scale factor, $L$ is the gauge length of the tested fiber bundle, $d$ is the fiber diameter, and $m$ is the Weibull parameter which accounts for spread in the strength. Any nonuniform loading or misalignment of fibers within the fiber bundle can result in error in the bundle strength measurements.

A simpler method of calculating the bundle strength of fibers is from tensile test data on individual fibers removed from the composite. If the average tensile strength of a fiber population, $\sigma$, and its weibull modulus, $m$, are known, then the bundle strength can be calculated from the relationship (Ref. 13),

$$
\frac{\sigma_{f}^{8}}{\sigma}=(m e)^{-1 / m} / \Gamma[(m+1) / m] .
$$

Here $\Gamma$ is the gamma function and the other symbols have their usual meaning. Both of these methods require removal of fiber from the composite. In the case of SIC/RBSN composites, however, it is difficult to remove sic fibers from 
the composite matrix. The solvents used to dissolve the RBSN matrix invariably affect the fiber surface and introduce a different set of flaw populations that is not representative of the fibers in the as-fabricated composite. On the other hand, if we assume that the average tensile strength of individual SiC fibers that were heat-treated under composite processing conditions is similar to that of the fibers in the composite, then the bundle strength can be estimated. The above assumption is valid for two reasons: (1) during nitridation, the nitriding gases can easily permeate through the composite preform and can react with the fibers as they would with individual SiC fibers exposed to the fabrication environment; (2) SiC fibers are compatible with RBSN matrix and no known interfacial reaction occurs between SiC fibers and RBSN matrix that would introduce a different set of flaw populations on the fiber surface and cause fiber strength degradation.

To estimate the bundle strength of SiC fibers in RBSN composites, tensile tests were performed on 20 nitrogen-treated SiC fibers at gauge length of $25 \mathrm{~mm}$. The average tensile strength of the fibers was $286 \mathrm{MPa}$ with a standard deviation of $44 \mathrm{MPa}$ and with a Weibull modulus of 8.2 . Substituting $\mathrm{m}=8.2$ and $\sigma=286 \mathrm{MPa}$ in Eq. (11), the bundle strength was calculated. Using a calculated bundle strength value of $2.08 \mathrm{GPa}$ and $V_{f}=0.3$ in Eq. (9), we calculated an ultimate composite strength value of $624 \mathrm{MPa}$ which is nearly 10 percent lower than the measured value of $682 \pm 150 \mathrm{MPa}$. This shows that the predicted ultimate strength of the composite based on individual fiber strength data for heat treated SiC fibers will probably yield a lower bound for strength.

In general, both the first matrix cracking stress and the ultimate composite strength should show gauge length dependency. Since large diameter SiC fibers do not effectively bridge the matrix flaws in SiC/RBSN composite, the matrix cracking stress should depend on the largest flaw within the tested 
volume. Obviously as the volume of tested material increases, the probability of finding a larger strength limiting flaw also increases. Therefore, the matrix cracking stress should decrease with increase in gauge length. The gauge length-independent matrix cracking behavior observed for SiC/RBSN suggests that the strength controlling flaws are uniformly distributed within the matrix.

According to Eq. (10) bundle strength is inversely related to the gauge length of the fiber bundle. Since ultimate tensile strength of the composite depends on bundle strength, ultimate tensile strength also should vary with the gauge length tested specimen. However, the results indicate no influence of gauge length on strength. To explain this behavior, a bundle theory that includes matrix effects must be developed.

Transverse strength. - There is no simple relation for predicting the transverse strength of fiber reinforced ceramic matrix composites (CMC). Unlike the longitudinal strength which is determined entirely by the fiber strength, the transverse strength is governed by many factors including the properties of the fiber and the matrix, the fiber/matrix interface bond strength, the distribution of matrix volds, and the internal stresses, etc. However, the transverse strength of a laminate with little or no bond between the fibers and matrix can be estimated by the strength of the matrix alone. Assuming that the weakly bonded fibers can be regarded as cylindrical holes $\left(E_{f}=0\right)$ and that the matrix is notch insensitive, transverse strength can be calculated from the equation (Ref.6),

$$
\sigma_{2}=\sigma_{m}\left[1-2\left(V_{f} / \pi\right)^{1 / 2}\right] \text {. }
$$

Substituting $V_{f}=0.3$ and $\sigma_{m}=84 \mathrm{MPa}$ from Table I in Eq. (12), the calculated value for $\sigma_{2}$ is $32 \mathrm{MPa}$ which closely agrees with the measured value of $27 \mathrm{MPa}$. This further indicates that the SiC/RBSN composite behaves as a weakly bonded composite. Even in this weakly bonded system, further 
improvements in the transverse strength appear possible by increasing the matrix strength. Assuming matrix strength can be increased to about $400 \mathrm{MPa}, \mathrm{a}$ typical tensile strength of commercially available dense $\mathrm{Si}_{3} \mathrm{~N}_{4}$, then $\mathrm{Eq}$. (12) predicts that the transverse strength of the composite can be increased to about $153 \mathrm{MPa}$. Another strengthening method would be to increase the bond strength between SiC fiber and RBSN matrix, but this may also lead to loss in axial properties and toughness.

TWO-DIMENSIONAL LAMINATES

Although the SiC/RBSN unidirectional laminates have excellent properties along the fiber direction, they cannot be used for multiaxial load bearing applications because they exhibit poor elastic and strength properties in other directions. The two previously suggested methods for improving the transverse strength may not sufficiently minimize this structural anisotropy problem. An effective method of circumventing this problem is by two-dimensional reinforcement. In this section the mechanical behavior of the two-dimensional laminates are analyzed and an attempt is made to predict their stiffness and strength properties from laminate theory.

\section{Elastic Properties}

Since two-dimensional laminates are composed of unidirectional lamina oriented at certain directions, $\theta$, with respect to each other, and since the stress-strain relationship for each lamina is known, the average stress in the two-dimensional laminate at any given strain level can be obtained from the summation of stresses in each lamina. Thus, when a two-dimensional laminate is tested in plane stress conditions along the principle directions, its stress-strain relation is represented by (Ref. 14)

$$
\left|\begin{array}{l}
\sigma_{11} \\
\sigma_{22} \\
\tau_{12}
\end{array}\right|=\left|\begin{array}{l}
A_{11} A_{12} A_{16} \\
A_{12} A_{22} A_{26} \\
A_{16} A_{26} A_{66}
\end{array}\right|\left|\begin{array}{l}
\varepsilon_{11} \\
\varepsilon_{22} \\
Y_{12}
\end{array}\right|
$$


where $\sigma, \tau, \gamma$ and $\varepsilon$ have their usual meaning, and $A_{i j}$ represents the reduced stiffness matrix which is obtained by summing the stiffness of the individual plies,

$$
A_{i j}=\Sigma_{k=1}^{N}\left(Q_{i j}\right)_{k}\left(t_{k}-t_{k-1}\right)
$$

where $N$ is the number of plies and $t$ is thickness of $k^{\text {th }}$ ply in the composite. Thus knowing the reduced stiffness matrix, $A_{i j}$, for the twodimensional laminate, its effective engineering elastic constants and its stress-strain relationship before matrix fracture can be determined (Ref. 14). The relationship between the engineering constants and the reduced stiffness constants are as follows:

$$
\begin{gathered}
E_{x x}=\left(A_{11} A_{22}-A_{12}^{2}\right) / A_{22} \\
E_{y y}=\left(A_{11} A_{22}-A_{12}^{2}\right) / A_{11} \\
\nu_{x y}=A_{12} / A_{22} \\
G_{x y}=A_{66} .
\end{gathered}
$$

Thus, knowing the properties, stacking sequence, orientation, and thickness of each lamina within the laminate, laminate properties can be predicted. Using the four elastic constants, $E_{11}, E_{22}, v_{12}$, and $G_{12}$ calculated from constituent properties for weakly bonded unidirectional SiC/RBSN laminates, Eqs. (14) to (17) were employed to calculate the engineering properties of cross-ply and angle-ply composites. The results of these calculations and the measured data are presented in Table IV. Good agreement exist between the predicted values and the measured data. The scatter in the data is probably due to variations in matrix properties, fiber volume fraction, and misorientation of fibers from specimen to specimen. 


\section{Strength Properties}

As discussed previously, the stress-strain behavior for the cross-ply and angle-ply laminates, showed a linear region in the initial stages of deformation similar to that of unidirectional composites stressed along the reinforcement direction. For any given strain, up to matrix fracture, stress in the composite can be obtained from Hooke's law,

$$
\sigma_{A}=E_{A} \varepsilon_{A}
$$

where $E_{A}$ is the elastic modulus of the laminate and $\varepsilon_{A}$ is its strain. For a given laminate construction, it is possible to calculate $E_{A}$ from constitutive properties and laminate theory. The matrix fracture strain remains invariant irrespective of fiber lay-up in the laminates and corresponds to 0.1 percent. Therefore, knowing $E_{A}$ and $\varepsilon_{A}$, matrix fracture stress can be predicted from Eq. (18). Similar to unidirectional composites, the matrix fracture stress of angle-ply and crossed-ply laminates can be further improved by increasing the matrix density, strengthening the fiber/matrix bonding, increasing fiber volume content, or employing small diameter fibers as reinforcement.

Behavior of angle-ply laminates beyond the matrix fracture stress is difficult to predict because of the complicated state of stress, but that of cross-ply laminates can be analyzed using the argument offered earlier for unidirectional laminates. For $\left[\mathrm{O}_{2} / 90_{2}\right] \mathrm{s}$ laminates, after the matrix is cracked, part of the load carried by it is transferred to the fiber along the stressing direction. As the stressing is continued, the remaining segments of the matrix are stressed until they crack again and this process continues until the matrix no longer cracks. Beyond this region, a second linear region was seen until the composite ultimately fractured. The secondary modulus for the cross-ply laminates depends on the volume fraction of fibers along the loading direction and can be estimated from Eq. (A-I), assuming zero 
contribution from transverse fibers and the RBSN matrix. For $V_{f 0}=$ 0.15 percent (one half of the total volume fraction of fibers in the laminate) and $E_{f}=390 \mathrm{GPa}$, the calculated value of $E_{s}$ is $58 \mathrm{GPa}$ which is nearly 20 percent greater than the measured value of $45 \mathrm{GPa}$. This discrepancy is probably due the error in the fiber volume fraction value used in the calculation.

Because the matrix is cracked and the fibers in transverse directions are decoupled from the matrix, the deformation of the cross-ply composite beyond the nonlinear region is controlled by fibers along the loading direction. The ultimate strength of the composite is proportional to the bundle strength of fibers along the fiber direction and can be estimated from Eq. ( 9 ). Substituting $\sigma_{f}^{B}=2.08 \mathrm{GPa}$ and $V_{f}=0.15$ percent - one half of the total volume fraction of fiber contained in the composite in Eq. (9), the estimated value of ultimate strength is $312 \mathrm{MPa}$. This value closely agrees with the measured ultimate tensile strength value of $294 \pm 87 \mathrm{MPa}$.

\section{SUMMARY OF RESULTS}

The room temperature mechanical properties of unidirectional, cross-ply, and angle-ply SiC/RBSN composite laminates have been measured and the applicability of laminate theory to predict their elastic and strength properties has been explored. The influence of notch and specimen gauge length on the axial properties of the $[0]_{8}$ laminates have been determined. The important findings are as follows:

1. The unidirectionally reinforced composite laminates had highly anisotropic in-plane properties.

2. The $[0]_{8}$ laminates, when stressed along the fiber direction, displayed linear stress-strain behavior to first matrix cracking stress. Beyond this stress level they showed a metal-like stress-strain behavior, and at the ultimate stress they fractured catastrophically with broomy fracture. In 
contrast, off-axis laminates showed only one linear region with ultimate fracture caused by shear and debonding of the fiber from the matrix.

3. Unidirectional laminates tested along the reinforcement direction showed no loss in mechanical properties due to gauge length variation or machined notches normal to the fiber direction.

4. Orientation of unidirectional lamina in $\left[\mathrm{O}_{2} / 90_{2}\right] \mathrm{s}$ or $\left[+45_{2} /-45_{2}\right] \mathrm{s}$ lay-ups had no significant influence on the composite matrix fracture strain, but did influence composite modulus, matrix first cracking strength, and ultimate strength.

5. Simple equations were developed for predicting the elastic and strength properties of weakly bonded unidirectional, cross-ply, and angle-ply SiC/RBSN composite laminates. These equations use composite theory with minor modifications to account for weak bonding between fiber/matrix. 


\section{APPENDIX A. - CALCULATION OF ELASTIC CONSTANTS}

\section{ELASTIC MODULI $E_{12}$ AND $E_{22}$}

The elastic modulus, $E_{11}$, along the fiber direction for a well bonded composite can be estimated from the rule of mixtures:

$$
E_{c}=E_{f} V_{f}+E_{m} V_{m}
$$

where $E$ is Elastic modulus, $V$ is the volume fraction, and the subscripts $c$, $f$, and $m$ refer to the composite, fiber, and matrix, respectively. Using values of $E_{f}=390 \mathrm{GPa}$ for SiC fibers (Ref. 12), $E_{m}=110 \mathrm{GPa}$ for RBSN from Table I, and $V_{f}=0.3$, our calculated value of $E_{C}$ for SiC/RBSN is $194 \mathrm{GPa}$ which is in reasonable agreement with the measured value of $E_{C}=193 \mathrm{GPa}$. If the fiber contribution were zero in Eq. $(A-1)$, the composite modulus would be $77 \mathrm{GPa}$ which is half that of the measured value. Therefore, it appears that SiC/RBSN composite behaves as well-bonded composite when stressed along the fiber direction, and the rule of mixtures can be employed for predicting the primary modulus of this composite.

Of the four elastic constants, transverse modulus, $E_{22}$, is probably one of the most difficult constants to predict. For a well-bonded composite, E22 can be predicted from the Halpin-Tsai equation (Ref. 6),

$$
E_{22}=E_{2 m}\left(1+c_{2} \Pi_{2} V_{f}\right) /\left(1-n_{2} V_{f}\right) \text {. }
$$

where

$$
n_{2}=\left(E_{2 f} / E_{2 m}-1\right) /\left(E_{2 f} / E_{2 m}+\zeta\right) .
$$

The terms $E_{2 f}, E_{2 m}$, and $\xi$ refer to the transverse modulus of the fiber, the transverse modulus of the matrix, and a fiber packing geometric factor, respectively. Assuming the fiber modulus in the transverse direction is the same as that in the axial direction, and using values of $E_{f}=390 \mathrm{GPa}$ (Ref. 12), $E_{m}=110 \mathrm{GPa}$ and $V_{f}=0.3$ from Table $I$ and $\xi=2$ for square packing, the transverse modulus was calculated. This calculation yields a value of $162 \mathrm{GPa}$ for $E_{22}$, which is more than twice the measured value of 
$69 \mathrm{GPa}$. Such a large difference between the measured and calculated transverse modulus implies poor load transfer between the SiC fiber and RBSN matrix. Nonetheless, the calculated value of $162 \mathrm{GPa}$ reflects the maximum transverse modulus that can be attained, provided the fiber contributes to the transverse modulus.

On the other hand, if we assume that Sic fibers do not contribute to the transverse properties, that is, $E_{2 f}=0, E q .(A-2)$ reduces to

$$
E_{22}=2 E_{2 m}\left(1-V_{f}\right) /\left(2+V_{f}\right) \text {. }
$$

Substituting previously used values for $E_{2 m}$ and $V_{f}$ in Eq. (A-3), we obtained a value of $67 \mathrm{GPa}$ for $E_{22}$, which closely agrees with the measured value of $69 \mathrm{GPa}$. This fact suggests that in transverse direction, the SiC/RBSN fiber-matrix bond is effectively nonexistent. It also suggests that in general the modified Halpin-Tsai Eq. (A-3) may be a good predictive equation for weakly bonded CMC.

\section{POISSON'S RATIO}

Poisson's ratio for unidirectional composites can be obtained from the rule of mixtures

$$
v_{12}=v_{12 f} V_{f}+v_{12 m} V_{m} \text {. }
$$

The terms $v 12 f$ and $v 12 m$ refer to Poisson's ratio for the fiber and the matrix respectively. The other symbols have their usual meaning. Using $\nu_{12 f}=0.17$ (Ref. 12) $\nu_{12 m}=0.22$ (Table I), $V_{f}=0.3$, the calculated value of Poisson's ratio for the SiC/RBSN composites is 0.21 which is same as that measured for the composite (Table I).

IN PLANE SHEAR MODULUS, $G_{12}$

For unidirectional composites the in-plane shear modulus, $G_{12}$, can be estimated from the relation (Ref. 6),

$$
G_{12}=G_{12 m}\left[G_{12 f}\left(1+V_{f}\right)+G_{12 m}\left(1-V_{f}\right)\right] / G_{12 f}\left(1-V_{f}\right)+G_{12 m}\left(1+V_{f}\right)
$$


where $G_{12 f}$ and $G_{12 m}$ are the in-plane shear moduli for the fiber and the matrix respectively. Assuming SiC fiber and RBSN matrix are isotropic materials, their shear moduli can be calculated from Eq. (1) and using values of $E_{f}=390 \mathrm{GPa}$ and $v_{12 f}=0.17$ (Ref. 12), and $E_{m}=110 \mathrm{GPa}$ and $v_{12 \mathrm{~m}}=0.22$ from Table I. Using calculated shear modulus values for $G_{12 f}=167 \mathrm{GPa}$ and $G_{12 m}=45 \mathrm{GPa}, V_{f}=0.3$ and $E q .(A-5)$, in-plane shear modulus for SiC/RBSN composite was calculated. The calculated value of $63 \mathrm{GPa}$ is an over estimation of the measured value of $31 \mathrm{GPa}$. This again suggests that the composite is not behaving as strongly bonded material. On the other hand if we assume that fiber contribution is zero in $E q .(A-5)$, that is $E_{12 f}=0$, it can be reduced to

$$
G_{12}=G_{12 m}\left[\left(1-V_{f}\right) /\left(1+V_{f}\right)\right] \text {. }
$$

Using previously used value of $G_{12 m}=45 \mathrm{GPa}$ and $V_{f}=0.3$, the calculated value of $\mathrm{G}_{12}$ is $24 \mathrm{GPa}$ which more closely agrees with the measured value of $31 \mathrm{GPa}$. 


\section{APPENDIX B. - INTERFACIAL SHEAR STRENGTH}

The interfacial shear strength $\tau$ between the fiber and the matrix can be obtained from the equation derived by Aveston, Cooper and Kelly (Ref. 10),

$$
\tau=\sigma_{c}^{f} D /\left\{2.98 \times V_{f}\left[1+E_{f} V_{f} / E_{m}\left(1-V_{f}\right)\right]\right\}
$$

where $\sigma_{c}^{f}$ is the composite stress at which matrix first cracks, $x$ is the mean separation between the matrix cracks, $D$ is the fiber diameter, $E_{f}$ is the fiber modulus, $E_{m}$ is the matrix modulus, and $V_{f}$ is the volume fraction of the fiber. Substituting $E_{f}=390 \mathrm{GPa}, E_{m}=110 \mathrm{GPa}, V_{f}=0.3, x=0.8$, $D=142 \mu \mathrm{m}$ and $\sigma_{C}^{f}=227 \mathrm{MPa}$ in Eq. (B-1) the calculated value of $\tau$ is $18 \mathrm{MPa}$. 


\section{REFERENCES}

1. R.T. Bhatt, "Mechanical Properties of SiC Fiber Reinforced ReactionBonded $\mathrm{Si}_{3} \mathrm{~N}_{4}$ Composites," NASA TM-87085 (1985).

2. J.W. Lucek, G.A. Rossetti, Jr., and S.D. Hartline, "Stability of Continuous Si-C (-0) Reinforcing Elements in Reaction-Bonded Sllicon Nitride Process Environments," pp. 27-38 in Metal Matrix, Carbon, and Ceramic Matrix Composites 1985. NASA CP-2406, J.D.Buckley, ed., NASA, Washington, D.C. (1985).

3. R.T. Bhatt, "Effect of Fabrication Conditions on the Properties of SiC Fiber Reinforced Reaction-Bonded Silicon Nitride Matrix Composites (SiC/RBSN)," NASA TM-88814 (1986).

4. A.S. Jayatilaka, Fracture of Engineering Brittle Materials. Applied Science Publishers Ltd., London (1979).

5. B.D. Agarwal and L.J. Broutman, Analysis and Performance of Fiber Composites. John Wiley Publication (1982).

6. J.M. Whitney, I.M. Daniels, and R.B. Pipes, Experimental Mechanics of Fiber Reinforced Composite Materials, pp. 185-202, The Society for Experimental Stress Analysis, Brookfield Center, CT (1982).

7. S. Lee and M. Munro, Composites, 17: 13-22 (1986).

8. D. Hul1, An Introduction to Composite Materials. Cambridge University Press, New York, p. 108 (1981).

9. S.W. Tsai and H.T. Hahn, Introduction to Composite Materials. Technomic Publishing Co., Westport, CT (1980).

10. J. Aveston, G.A. Cooper, and A. Kelly, "Single and Multiple Frcture," pp. 15-26 in The Properties of Fiber Composites. IPC Science and Technology Press Ltd., Surrey, England (1971).

11. J.J. Brennen and K.M. Prewo, J. Mater. Sci., 17: 2371-2383 (1982). 
12. J.A. Dicarlo and W. Williams, "Dynamic Modulus and Damping of Boron, Silicon Carbide, and Alumina Fibers," NASA TM-81422 (1980).

13. H.T. Corten, pp. 27-105 in Modern Composite Materials. L.J. Broutman and R.H. Krock, eds., Addison-Wesley, New York (1967).

14. J.E. Ashton, J.C. Halpin, and P.H. Petit, Primer on Composite Materials: Analysis. Technomic Publishing Co., Stamford, CT (1969).

TABLE I. - ROOM TEMPERATURE TENSILE PROPERTY DATA FOR SIC/RBSN COMPOSITE LAMINATES $\left(V_{f} \sim 0.3\right)$

\begin{tabular}{|c|c|c|c|c|c|}
\hline \multirow{2}{*}{$\begin{array}{r}\text { Tensile } \\
\text { property }\end{array}$} & \multirow{2}{*}{$\begin{array}{l}\text { Unrein- } \\
\text { forced } \\
\text { RBSN }\end{array}$} & \multicolumn{4}{|c|}{ Composite laminate construction } \\
\hline & & {$[0]_{8}$} & {$[90]_{8}$} & {$\left[\mathrm{O}_{2} / 90_{2}\right]_{S}$} & {$\left[+45_{2} /-45_{2}\right]_{S}$} \\
\hline $\begin{array}{l}\text { Elastic constants } \\
E_{x x}, G P a \\
E_{s}, G P a \\
G_{x y}, G P a \\
v_{x y}\end{array}$ & $\begin{array}{c}110 \pm 14 \\
-0.22\end{array}$ & $\begin{array}{l}193 \pm 7 \\
103 \pm 12 \\
31 \pm 3 \\
0.21\end{array}$ & $\begin{array}{l}69 \pm 3 \\
-0 .- \\
0.08\end{array}$ & $\begin{array}{c}124 \pm 6 \\
45 \pm 7 \\
-0.12\end{array}$ & $\begin{array}{l}78 \pm 3 \\
-0.36\end{array}$ \\
\hline $\begin{array}{l}\text { Tensile strength, MPa } \\
\text { Matrix, om } \\
\text { Ultimate, outs }\end{array}$ & $84 \pm 26$ & $\begin{array}{l}227 \pm 41 \\
682 \pm 150\end{array}$ & ---- & $\begin{array}{l}127 \pm 26 \\
294 \pm 87\end{array}$ & $\begin{array}{l}75 \pm 10 \\
88 \pm 16\end{array}$ \\
\hline $\begin{array}{l}\text { Strain, percent } \\
\text { Matrix, } \varepsilon_{m} \\
\text { Ultimate, } \varepsilon_{\text {uts }}\end{array}$ & $\begin{array}{l}.08 \\
.08\end{array}$ & $\begin{array}{l}.11 \\
.45\end{array}$ & $\begin{array}{l}.03 \\
.03\end{array}$ & $\begin{array}{l}.1 \\
.6\end{array}$ & $\begin{array}{l}.1 \\
.2\end{array}$ \\
\hline
\end{tabular}

TABLE II . - INFLUENCE OF GAGE LENGTH ON ROOM TEMPERATURE

TENSILE STRENGTH FOR SIC/RBSN COMPOSITE $[0]_{8}$ LAMINATES $\left(V_{f} \sim 0.3\right)$

\begin{tabular}{|c|c|c|}
\hline $\begin{array}{c}\text { Gage } \\
\text { length, } \\
\mathrm{mm}\end{array}$ & $\begin{array}{c}\text { Matrix } \\
\text { cracking } \\
\text { stress, } \\
\text { MPa }\end{array}$ & $\begin{array}{c}\text { Ultimate } \\
\text { tensile } \\
\text { strength, } \\
\text { MPa }\end{array}$ \\
\hline 12.7 & $233 \pm 30$ & $660 \pm 148$ \\
25.4 & $277 \pm 41$ & $682 \pm 150$ \\
50.8 & $288 \pm 22$ & $704 \pm 164$ \\
\hline
\end{tabular}

TABLE III. - ROOM TEMPERATURE TENSILE STRENGTH DATA FOR NOTCHED AND UNNOTCHED $[0]_{8}$ SIC/RBSN COMPOSITE LAMINATES

$$
\left(V_{f} \sim 0.3\right)
$$

\begin{tabular}{|l|c|c|}
\hline Specimen condition & $\begin{array}{c}\text { Matrix } \\
\text { cracking } \\
\text { stress, } \\
\text { MPa }\end{array}$ & $\begin{array}{c}\text { Ultimate } \\
\text { tensile } \\
\text { strength, } \\
\text { MPa }\end{array}$ \\
\hline Unnotched & $227 \pm 41$ & $686 \pm 150$ \\
Single notchedd & $201 \pm 12$ & $620 \pm 145$ \\
Double notchedd & $226 \pm 15$ & $659 \pm 135$ \\
\hline asingle notch length = 3.0 mm, specimen \\
width = $12 \mathrm{~mm}$, strength measured based \\
on net cross-sectional area; gauge length \\
$=25.4 \mathrm{~mm}$.
\end{tabular}


TABLE IV. - COMPARISON OF MEASURED AND PREDICTED ELASTIC PROPERTIES OF $\left[0_{2} / 90_{2}\right] S$ AND $\left[+45_{2} /-45_{2}\right] S$ SiC/RBSN COMPOSITE LAMINATE $\left(V_{f} \sim 0.3\right)$

\begin{tabular}{|c|c|c|c|c|}
\hline \multirow{2}{*}{$\begin{array}{c}\text { Elastic } \\
\text { Property }\end{array}$} & \multicolumn{2}{|c|}{$\left[\mathrm{O}_{2} / 90_{2}\right]_{S}$ Laminate } & \multicolumn{2}{c|}{$\left[+45_{2} /-45_{2}\right]_{S}$ Laminate } \\
\cline { 2 - 5 } & Predicted & Measured & Predicted & Measured \\
\hline$E_{x x}, \mathrm{GPa}$ & $132 \pm 8$ & $124 \pm 6$ & $79 \pm 9$ & $78 \pm 5$ \\
$E_{y y}, \mathrm{GPa}$ & $132 \pm 8$ & $124 \pm 6$ & $79 \pm 9$ & $78 \pm 5$ \\
$v_{x y}, \mathrm{GPa}$ & 0.11 & 0.12 & 0.46 & 0.36 \\
$\mathrm{G}_{x y}, \mathrm{~Pa}$ & $27 \pm 7$ & $31 \pm 2$ & ---- & ---- \\
\hline
\end{tabular}

aPredicted values based on laminate theory for weaklybonded composites.

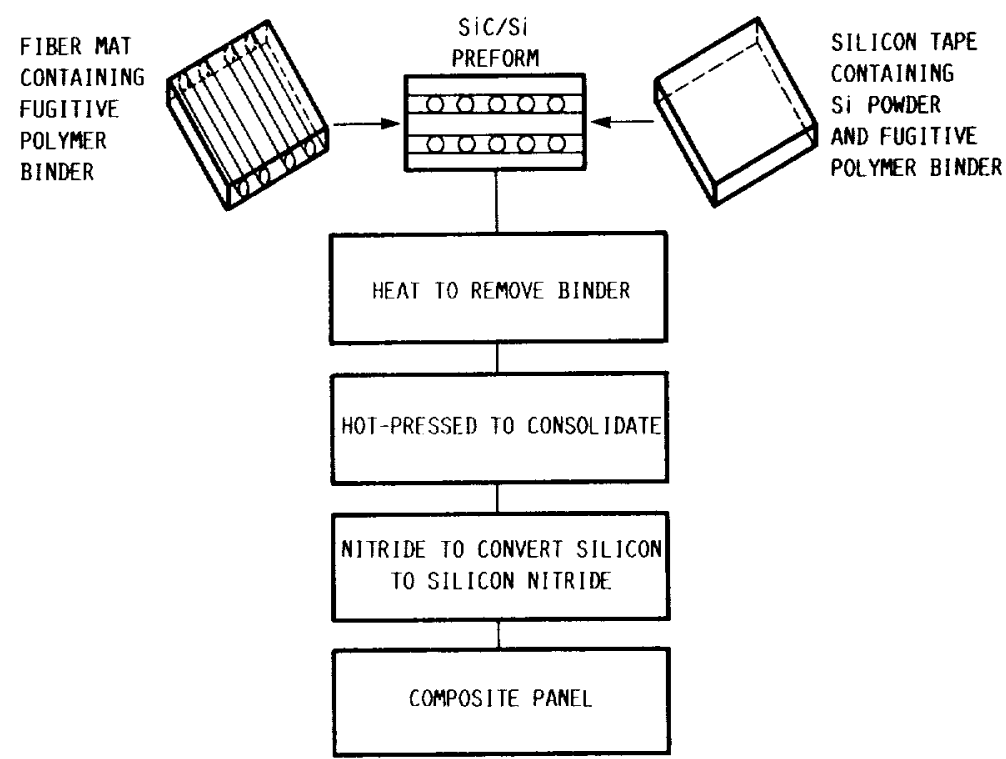

FIGURE 1. - SCHEMATIC DIAGRAM SHOWING FABRICATION OF SIC/RBSN COMPOSITES. 


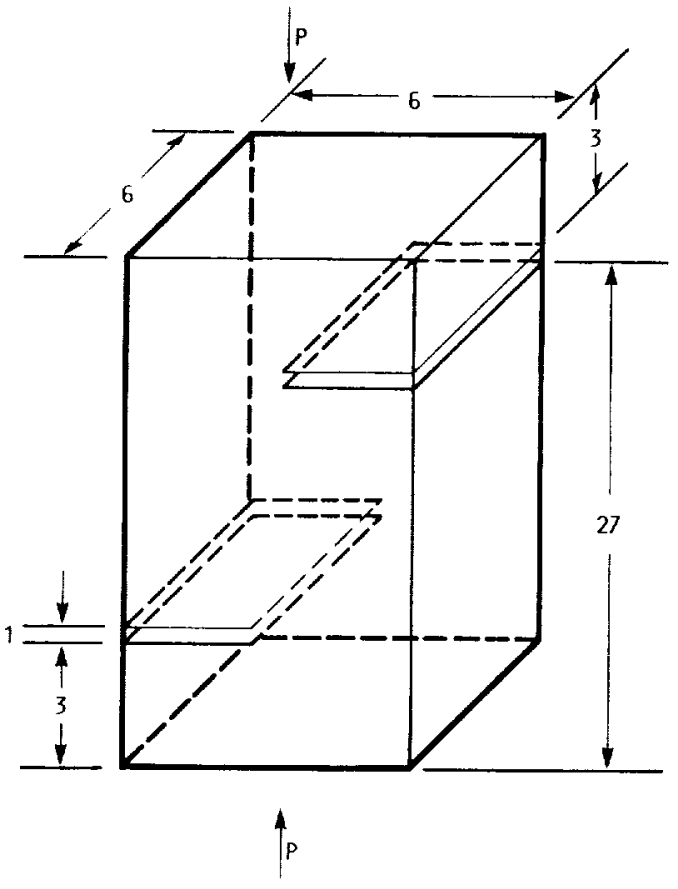

FIGURE 2. - DOUBLE EDGE NOTCHED SPECIMEN GEOMETRY FOR INTERLAMINAR SHEAR MEASUREMENT. DIMENSIONS IN MILL IMETERS.

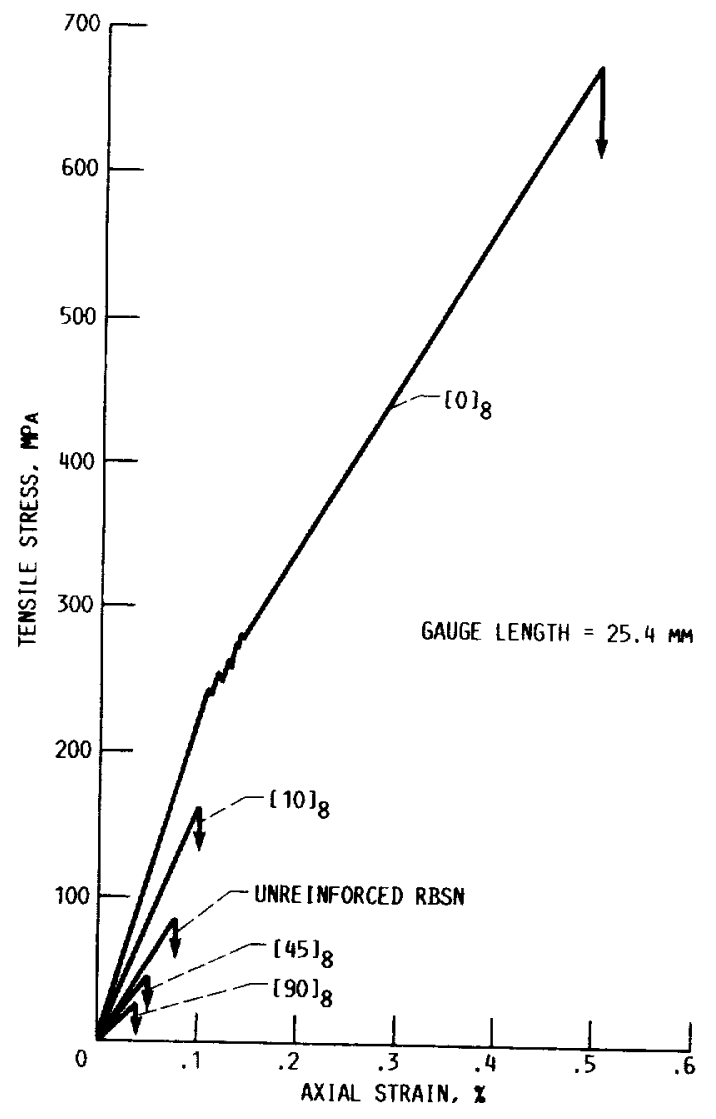

FIGURE 3. - ROOM TEMPERATURE STRESS-STRAIN BEHAVIOR FOR UNIDIRECTIONALLY REINFORCED SIC/RBSN COMPOSITE LAMINATES AND UNREINFORCED RBSH.

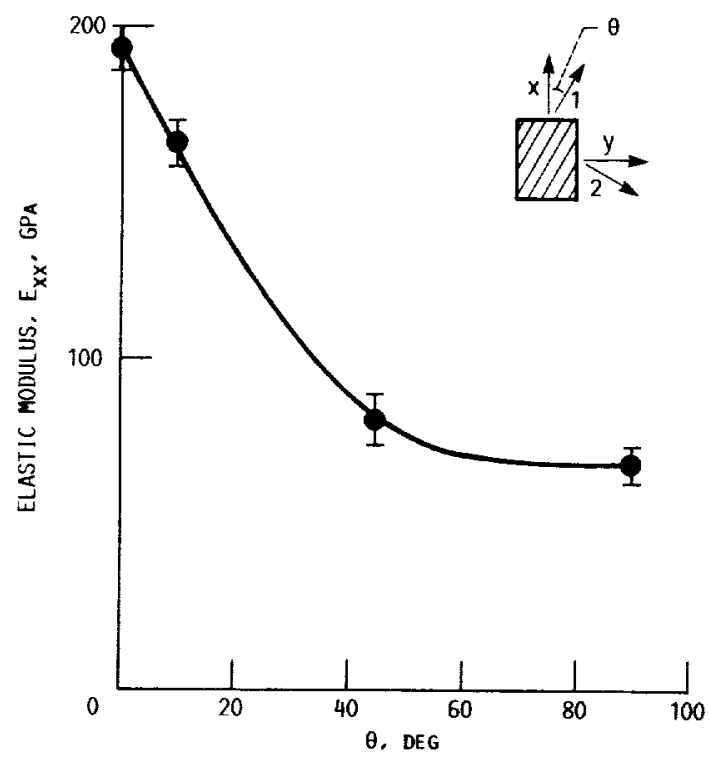

FIGURE 4. - VARIATION OF THE PRIMARY ELASTIC MODULUS OF UNIDIRECTIONALLY REINFORCED SIC/RBSN COMPOSITE LAMINATES WITH FIBER ORIENTATION. 


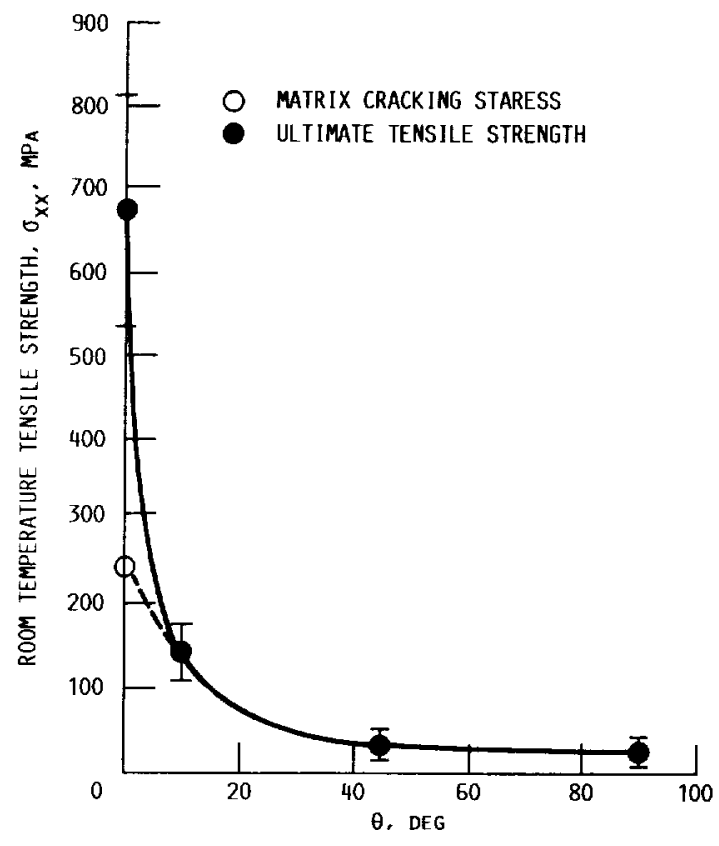

FIGURE 5. - VARIATION OF TENSILE STRENGTH OF UNIDIRECTIONALLY REINFORCED SIC/RBSN COMPOSITE LAMINATES WITH FIBER ORIENTATION.

\section{ORICINAL PAGE IS OF. POOR QUALTTY}

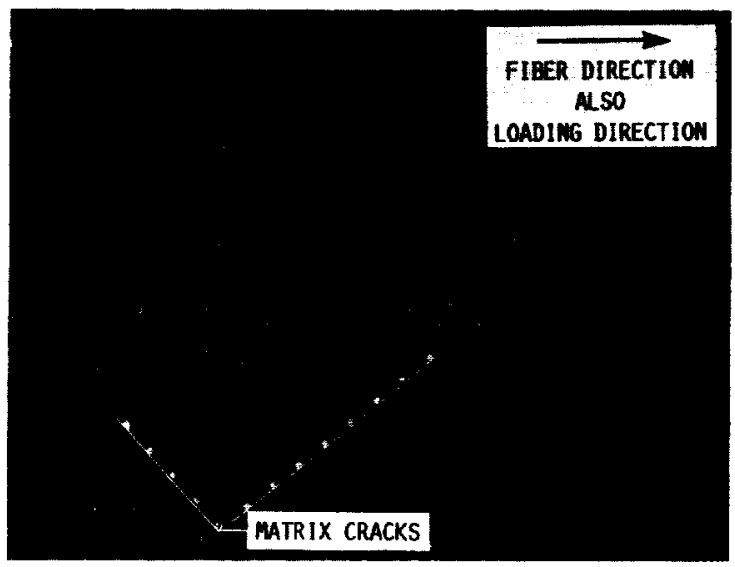

FIGURE 6. - OPTICAL PHOTOGRAPH OF A $[0]_{8}$ TENSILE SPECIMEN SIRESSED ABOVE THE LINEAR REGION SHOWING MATRIX CRACKING NORMAL TO THE LOADING DIRECTION.

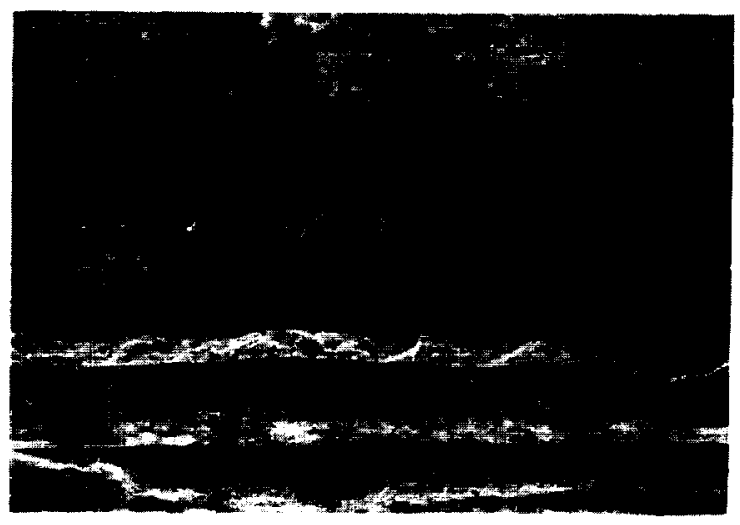

FIGURE 7. - OPTICAL PHOTOGRAPH SHOWING TYPICAL TENSILE FRACTURED SPECIMENS OF UNIDIRECTIONALLY REINFORCED SIC/RBSN LAMINATES: (a) $[0]_{8}$. (b) $[10]_{8}$. (c) $[45]_{8}$. AND (d) 190$]_{8}$.

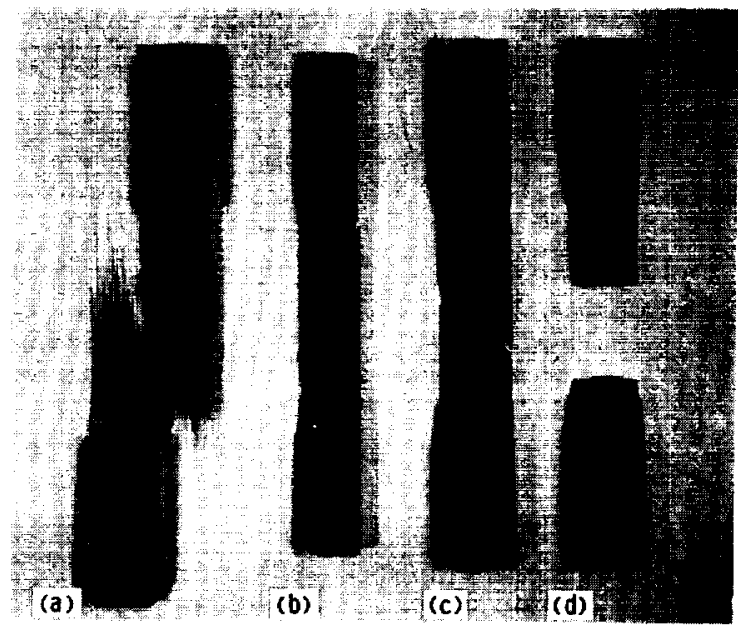

FIGURE 8. - SCANNING ELECTRON MICROGRAPH OF A FRACTURED [90] SPECIMEN SHOWING FIBER/MATRIX INTERFACE SPLITTING AS THE ORIGIN OF FAILURE. 


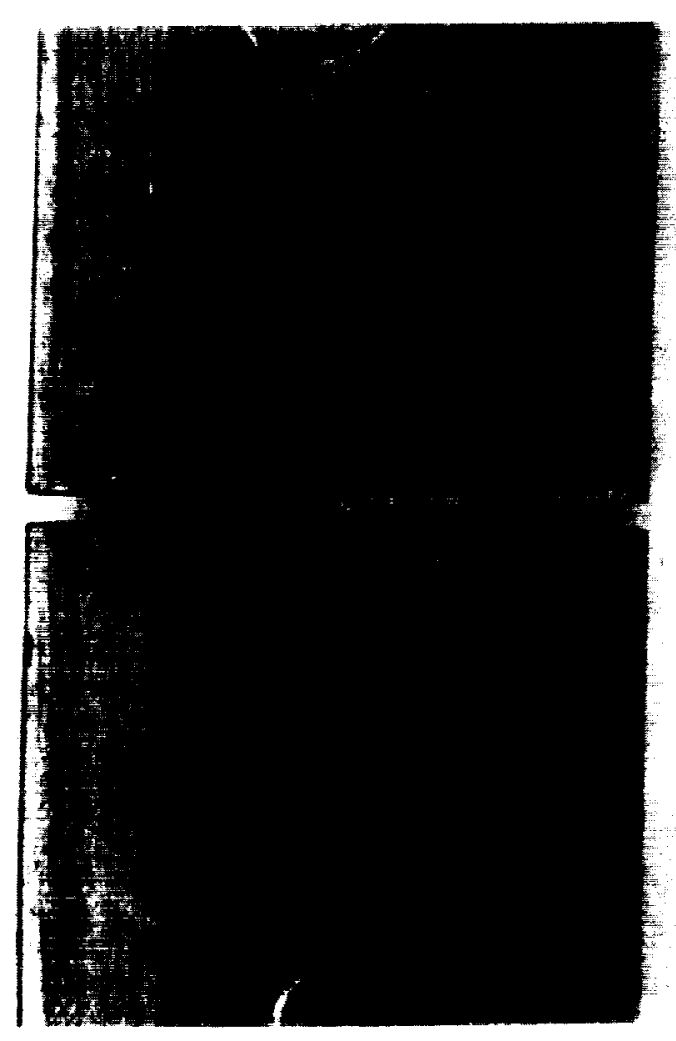

(a) BEFORE STRESSING, SHOWING NO VISIBLE CRACKS AT THE NOTCH TIP.

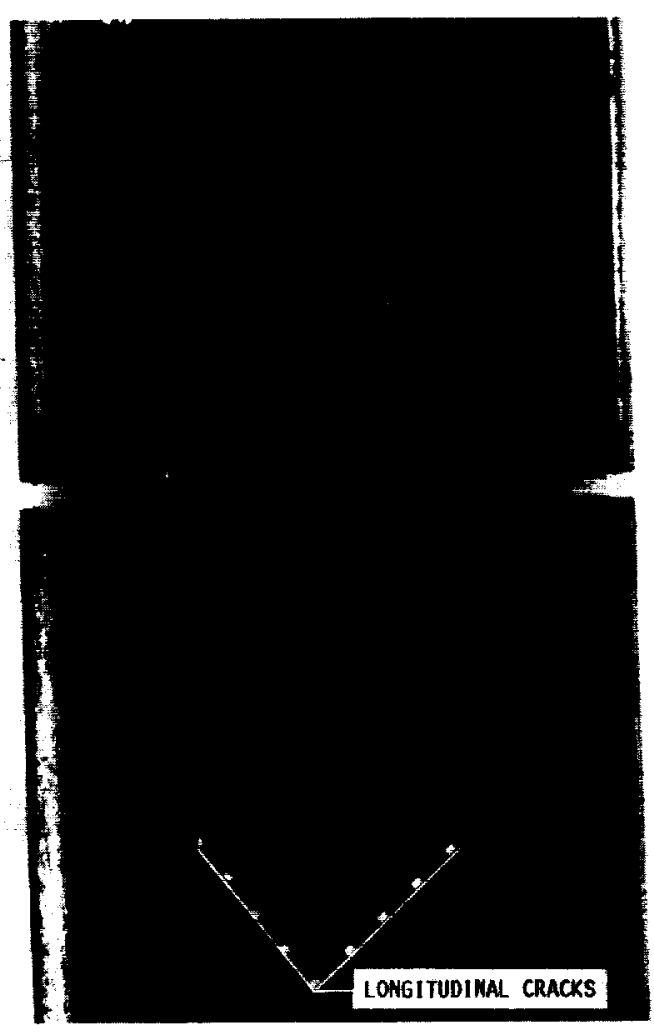

(b) AFTER STRESSING TO 65 MPA. SHOWING CRACKS MORMAL TO THE NOICH TIP.

FIGURE 9. - PHOTOMICROGRAPHS OF A DOUBLE EDGE NOTCHED TENSILE SPECIMEN.

DRBMALA PAGE HS of POOR QUALTY

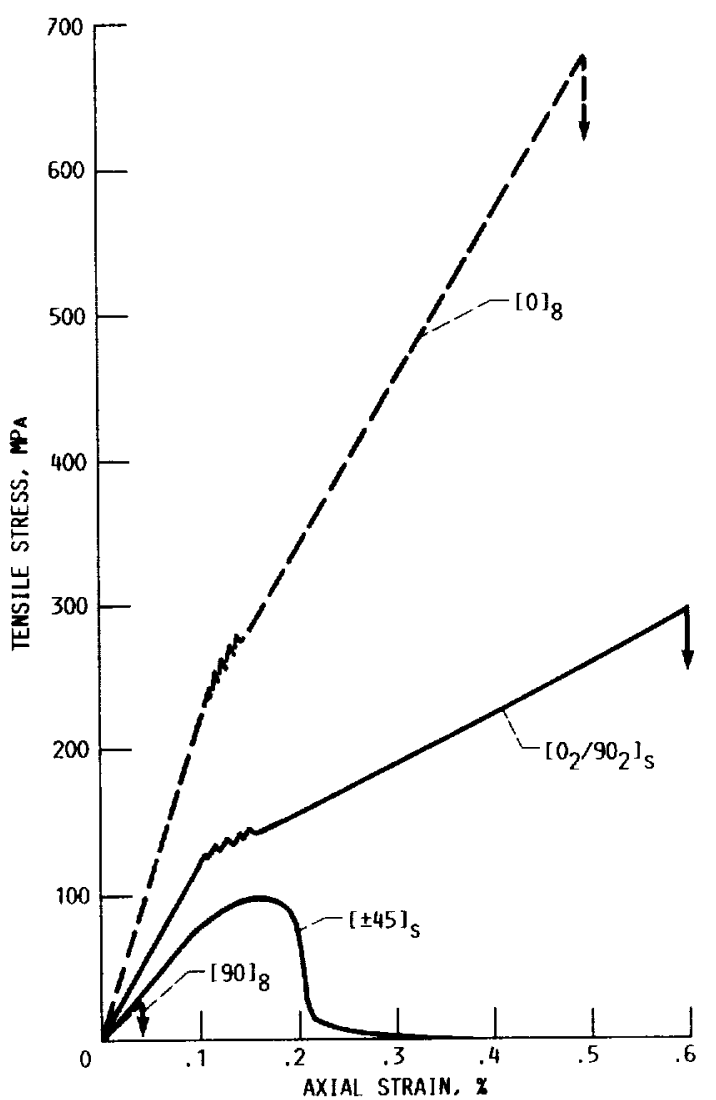

FIGURE 10. - ROOM TEMPERATURE STRESS-STRAIN BEHAVIOR FOR $\left[0_{2} / 90_{2}\right]_{S}$ AND $\left[ \pm 45_{2} /-45_{2}\right]_{S}$ LAMINATES. 


\section{ORIGINAL PAGE IS \\ OF POOR QUALITY}

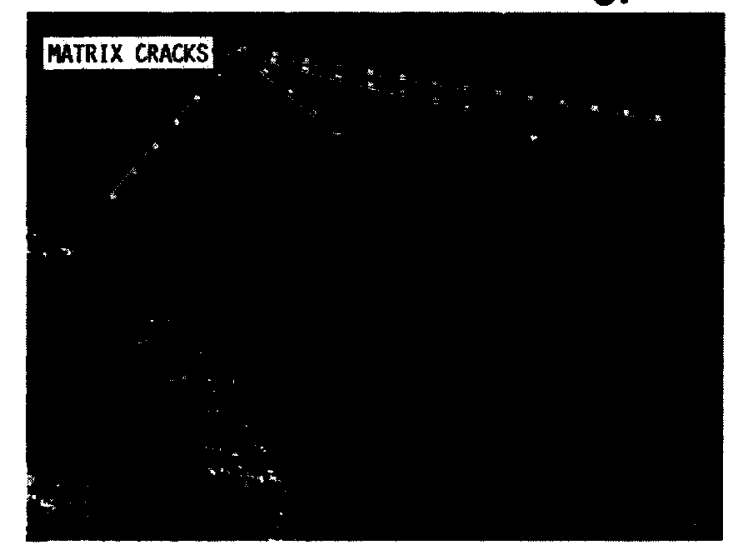

(a) $O=120 \mathrm{MPA}(T \mathrm{PP}$ VIEW).

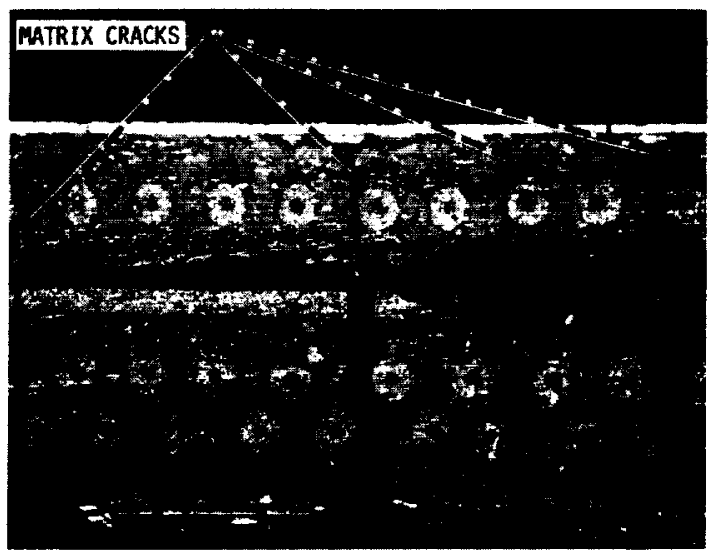

(c) $\sigma=250 \mathrm{MPA}$ (SIDE VIEW).

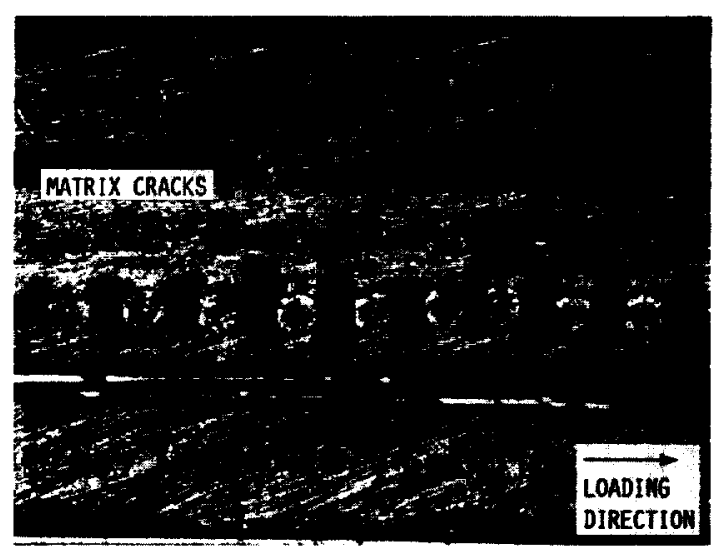

(b) $\sigma=120 \mathrm{MPA}$ (SIDE VIEW).

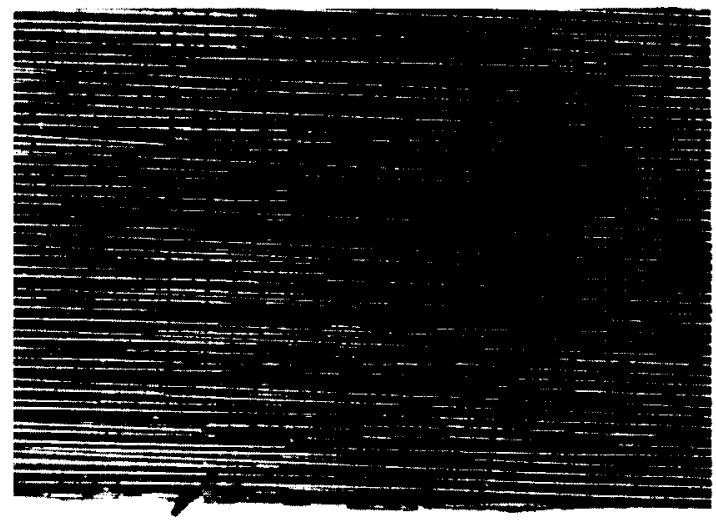

(d) $\sigma=300$ MPA (TOP VIEW).

FIGURE 11. - OPTICAL PHOTOGRAPHS OF A TYPICAL $\left.10_{2} / 90_{2}\right]_{S}$ LAMINATE STRESSED TO INDICATED STRESS LEVELS SHOHING PROGRESSION OF FAILURE.

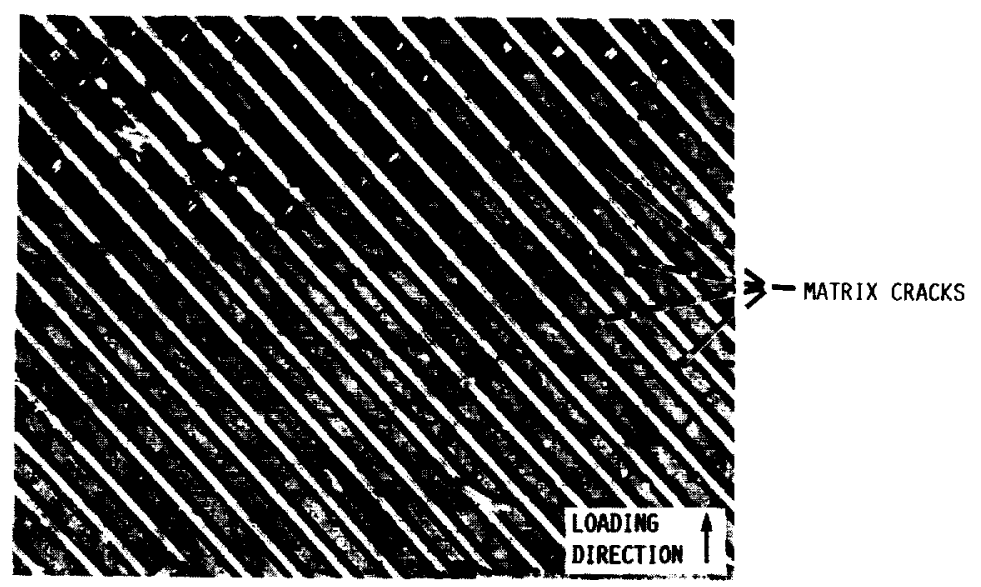

FIGURE 12. - FRACTURED SURFACE OF A TYPICAL $[+45 \% /-452]$ s LAMINATE SHOWING MATRIX CRACKING NORMAL TO LOADING DIRECTION, 


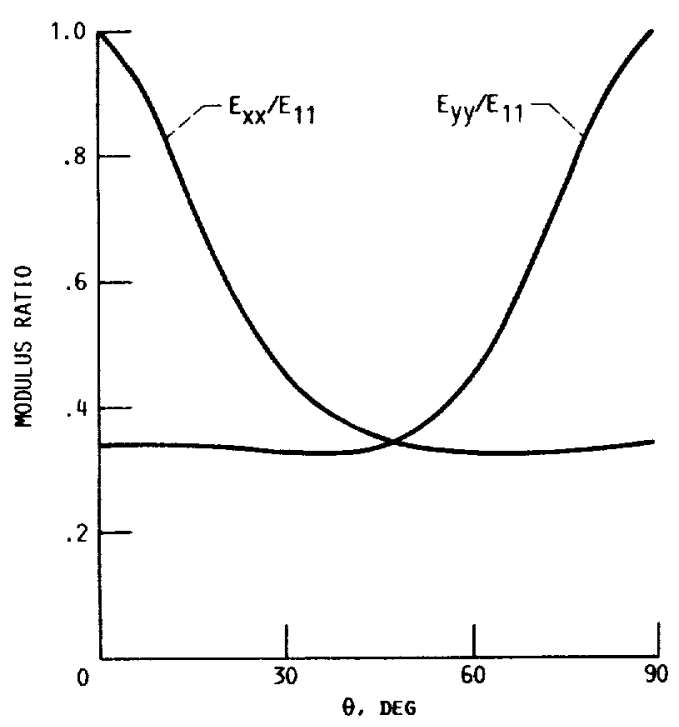

FIGURE 13. - VARIATION OF MODULUS RATIOS. $E_{x x} / E_{11}$ AND $E_{y y} / E_{22}$. WITH FIBER ORIENTATION PREDICTED FROM LAMINATE THEORY FOR WEAKLY BONDED UNIDIRECTIONAL LAMINATES OF SIC/RBSN COMPOSITES.

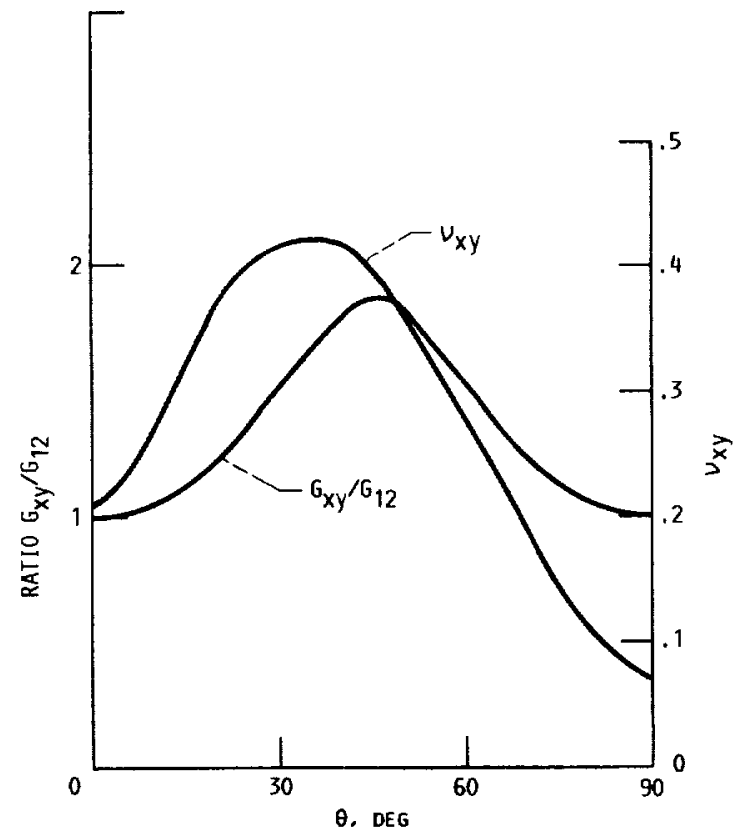

FIGURE 14. - VARIATION OF SHEAR MODULUS RATIO. $6_{x y} / G_{12}$, AND POISSON'S RAT $10, v_{x y}$, WITH FIBER ORIENTATION PREDICTED FROM LAMINATE THEORY FOR WEAKLY BONDED UNIDIRECTIONAL LAMINATES OF SIC/RBSN COMPOSITES.

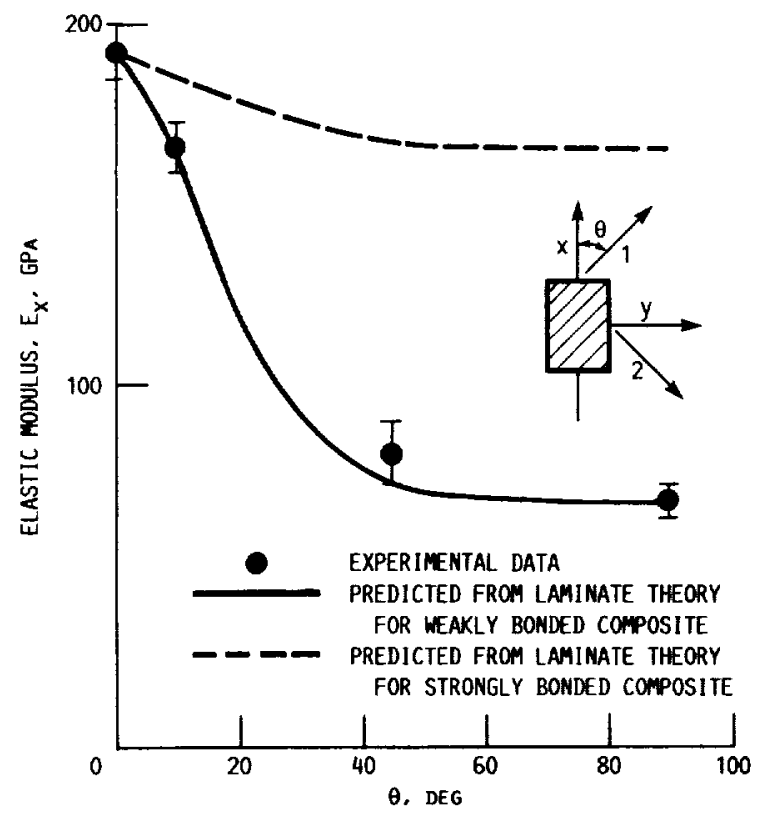

FIGURE 15. - COMPARISON OF ELASTIC MODULI WITH FIBER ORIENTATION PREDICTED FROM LAMINATE THEORY FOR WEAKLY AND STRONGLY BONDED UNIDIRECTIONAL LAMIMATES OF SIC/RBSN COMPOSITES, AND THE EXPERIMENTAL DATA. 


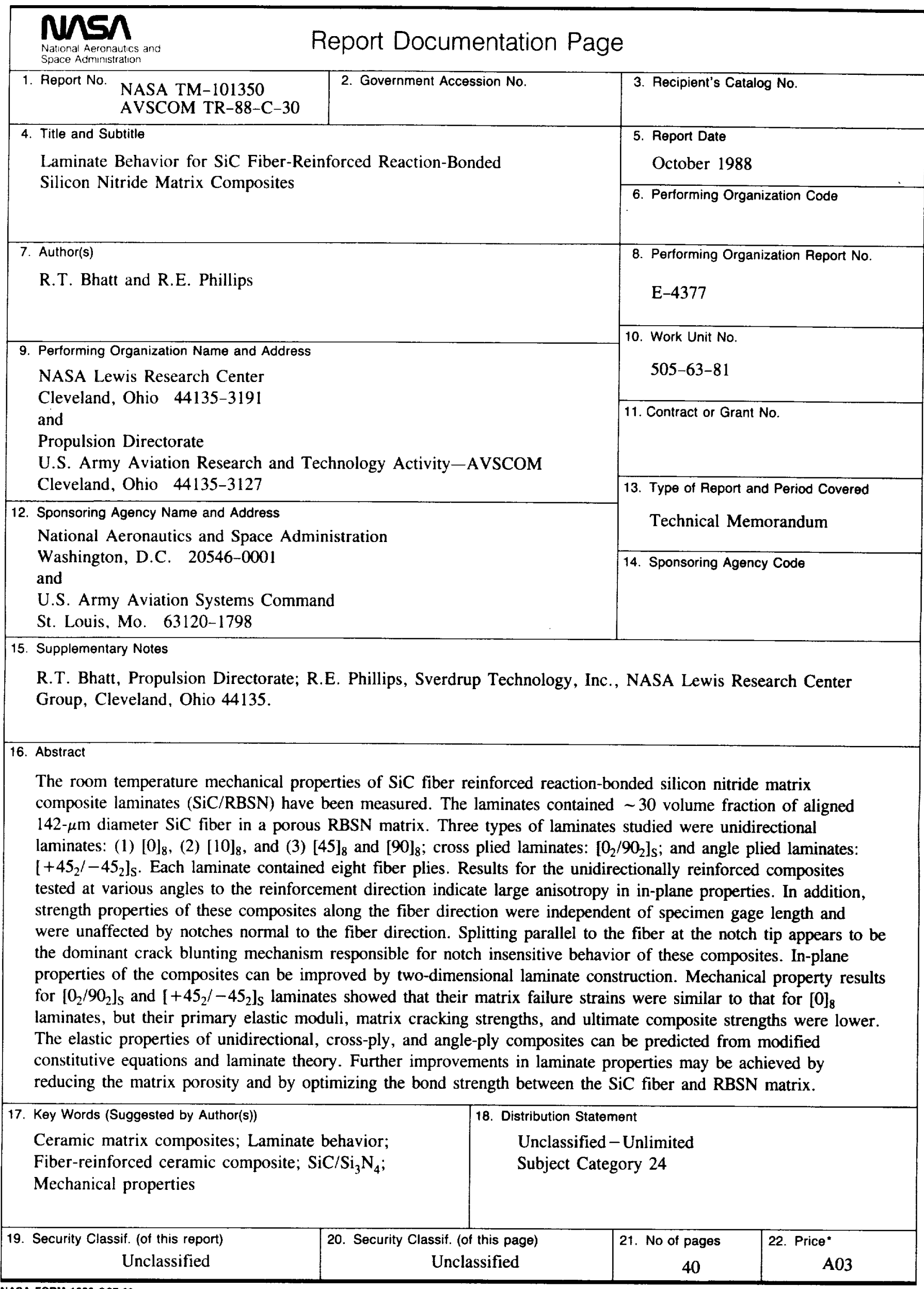


National Aeronautics and

Space Administration

Lewis Research Center

Cleveland, Ohio 44135

Orficial Buadnese

Penatiy for Private Uae $\$ 300$
FOURTH CLASS MAIL

ADDRESS CORRECTION REQUESTED

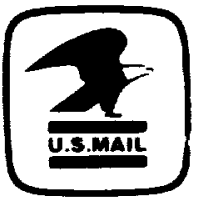

Posilage and Fees fiard Nationial Aerumathes and Spice Adrmintatur NASA 45 